\title{
Tuning ZnO Sensors Reactivity toward Volatile Organic Compounds via Ag Doping and Nanoparticle Functionalization
}

Vasile Postica, $^{\dagger}$ Alexander Vahl, ${ }^{\ddagger}$ David Santos-Carballal, ${ }^{*}, \perp$ Torben Dankwort, ${ }^{\S}$ Lorenz Kienle, $^{\S}$ Mathias Hoppe," Abdelaziz Cadi-Essadek, ${ }^{\perp}$ Nora H. de Leeuw, ${ }^{*, \perp, \#}$ Maik-Ivo Terasa," Rainer Adelung, ${ }^{*}, \|$ Franz Faupel, $*,+\circ$ and Oleg Lupan $*, \dagger, \|$

Center for Nanotechnology and Nanosensors, Department of Microelectronics and Biomedical Engineering, Technical University of Moldova, 168 Stefan cel Mare Av., MD-2004 Chisinau, Republic of Moldova

${ }^{\ddagger}$ Chair for Multicomponent Materials, Faculty of Engineering, Institute for Materials Science, ${ }^{\S}$ Synthesis and Real Structure, Institute for Materials Science, and "Functional Nanomaterials, Institute for Materials Science, Kiel University, Kaiserstr. 2, D-24143, Kiel, Germany

${ }^{\perp}$ School of Chemistry, Cardiff University, Main Building, Park Place, Cardiff CF10 3AT, United Kingdom

\#Department of Earth Sciences, Utrecht University, Princetonplein 8A, 3584 CD Utrecht, The Netherlands

\section{Supporting Information}

ABSTRACT: Nanomaterials for highly selective and sensitive sensors toward specific gas molecules of volatile organic compounds (VOCs) are most important in developing new-generation of detector devices, for example, for biomarkers of diseases as well as for continuous air quality monitoring. Here, we present an innovative preparation approach for engineering sensors, which allow for full control of the dopant concentrations and the nanoparticles functionalization of columnar material surfaces. The main outcome of this powerful design concept lies in fine-tuning the reactivity of the sensor surfaces toward the VOCs of interest. First, nanocolumnar and well-distributed Ag-doped zinc oxide ( $\mathrm{ZnO}: \mathrm{Ag})$ thin films are synthesized from chemical solution, and, at a second stage, noble nanoparticles of the required size are deposited using a gas aggregation source, ensuring that no percolating paths are formed between them. Typical

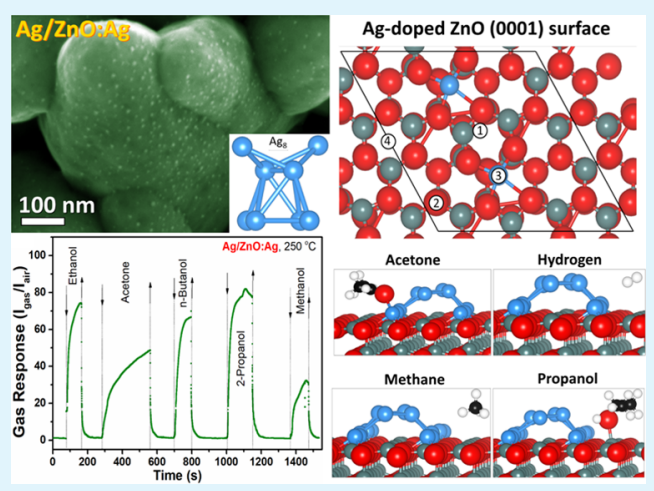
samples that were investigated are Ag-doped and $\mathrm{Ag}$ nanoparticlefunctionalized $\mathrm{ZnO}: \mathrm{Ag}$ nanocolumnar films. The highest responses to VOCs, in particular to $\left(\mathrm{CH}_{3}\right)_{2} \mathrm{CHOH}$, were obtained at a low operating temperature $\left(250{ }^{\circ} \mathrm{C}\right)$ for the samples synergistically enhanced with dopants and nanoparticles simultaneously. In addition, the response times, particularly the recovery times, are greatly reduced for the fully modified nanocolumnar thin films for a wide range of operating temperatures. The adsorption of propanol, acetone, methane, and hydrogen at various surface sites of the $\mathrm{Ag}$-doped $\mathrm{Ag}_{8} / \mathrm{ZnO}(0001)$ surface has been examined with the density functional theory (DFT) calculations to understand the preference for organic compounds and to confirm experimental results. The response of the synergistically enhanced sensors to gas molecules containing certain functional groups is in excellent agreement with density functional theory calculations performed in this work too. This new fabrication strategy can underpin the next generation of advanced materials for gas sensing applications and prevent VOC levels that are hazardous to human health and can cause environmental damages.

KEYWORDS: columnar films, VOC sensors, DFT, surface functionalization, Ag nanoparticles

\section{INTRODUCTION}

Advanced nanomaterials for gas sensing applications that have been traditionally used to detect volatile organic compound (VOC) levels, which are hazardous to human health and can cause environmental damages, are of high demand. However, a renewed and important interest in sensing nanomaterials has been driven by future applications in the identification of VOCs as biomarkers at early stage diseases. It is known that VOCs detected in exhaled breath at the ppb level can be related to several diseases. ${ }^{1}$ Conventional metal oxide sensors seldom offer reliable detection at such low levels and mostly cannot distinguish one VOC within a complex sample. Thus, an alternative strategy is required to fabricate new semiconducting oxide nanomaterials that are cost-effective, highly sensitive, and selective at the same time, allowing integration into a small portable device.

Zinc oxide $(\mathrm{ZnO})$ has a great potential for a wide range of applications, such as short-wavelength optoelectronics, photo-

Received: April 25, 2019

Accepted: July 23, 2019

Published: July 23, 2019 
catalysis, VOC and gas sensing, and UV detection among others. $^{2-5}$ The main advantages of $\mathrm{ZnO}$ micro and nanostructures are their semiconducting and piezoelectric properties, biocompatibility (structure- and concentrationdependent), and the possibility to grow this material in a wide range of morphologies. ${ }^{2}$ However, pure $\mathrm{ZnO}$ micro and nanostructures lack selectivity to specific gases, and the sensing properties are highly reduced by environmental humidity, which has led to a number of studies focused on overcoming these disadvantages. ${ }^{6,7}$ In this context, doping and/or surface functionalization/decoration with different noble metals was found to be very efficient in improving the selectivity and sensitivity of $\mathrm{ZnO}$ while reducing the influence of water vapors on the sensing properties. ${ }^{6,8-10}$

According to the theory of valence control in oxide semiconductors, ${ }^{11}$ the doping of $\mathrm{ZnO}$ with acceptor elements from the group I of the periodic table such as $\mathrm{Li}, \mathrm{K}, \mathrm{Cu}$, and $\mathrm{Ag}$ decreases its Debye length $\left(L_{\mathrm{D}}\right) \cdot{ }^{11}$ The doping of $\mathrm{ZnO}$ enhances the modulation of the surface electron depletion region, favoring the surface adsorption and desorption of oxygen species, which increases the response to VOCs. ${ }^{11-13}$ In particular, the Ag doping of $\mathrm{ZnO}$ micro and nanostructures/ columns is a very attractive method to improve the sensing properties due to the excellent catalytic properties of Ag. The dopant atoms also generate additional adsorption sites for ambient oxygen, and the target gas molecules effectively promote the interaction between the substrate surface and the adsorbate. $^{12}$ For example, Ag nanoparticles have been successfully used alongside nanowire networks of stoichiometric ${ }^{14}$ and nanoclusters of oxygen-deficient $\mathrm{SnO}_{2}$ for the detection of ethanol. ${ }^{15}$

In this work, we show that synergistically enhancing metal oxide surfaces using doping and noble nanoparticle functionalization is a promising approach for engineering gas sensor materials. To demonstrate this new concept, the Ag-doped and Ag NP-decorated $\mathrm{ZnO}$ nanocolumnar films are investigated, over a wide range of operating temperatures, to determine experimentally which functionalization method is optimal for enhancing the gas sensing properties toward VOC vapors. A possible gas sensing mechanism is proposed and discussed in detail. In this study, we have also used quantum mechanical simulations to investigate the $\mathrm{Ag}$ doping and the decoration with $\mathrm{Ag}_{8}$ clusters of the $\mathrm{ZnO}(0001)$ surface. We have evaluated the atomic charges and the electronic structure of different configurations to define the most stable geometry. Moreover, we have examined the adsorption of propanol, acetone, methane, and hydrogen at various surface sites of the Agdoped $\mathrm{Ag}_{8} / \mathrm{ZnO}(0001)$ to understand its preference for organic compounds.

\section{EXPERIMENTAL SECTION}

2.1. Synthesis of $\mathrm{ZnO}$ Nanocolumnar Thin Films. Ag-doped nanocolumnar $\mathrm{ZnO}$ films were grown on glass substrates to reduce possible budging. The glass substrates were cleaned and then sensitized as described in refs 16 and 17. Ag-doped nanocolumnar $\mathrm{ZnO}$ films were deposited on the substrates by the synthesis from chemical solution (SCS) method, as reported previously. ${ }^{16-21}$ The thickness of the columnar films in this study was about $1.5 \mu \mathrm{m}$. The $\mathrm{Ag}$ contents used in the samples were $0.50,0.95$, and $1.3 \mathrm{wt} \%$, which were achieved by adding 1.8, 5.3, and $12.3 \mathrm{mM}$ silver nitrate $\left(\mathrm{AgNO}_{3}\right)$ in complex solution, respectively. The content of $\mathrm{Ag}$ was measured using energy-dispersive X-ray (EDX) spectroscopy. All samples were treated by rapid thermal annealing (RTA) at $475{ }^{\circ} \mathrm{C}$ (marked as RTA475), $575{ }^{\circ} \mathrm{C}$ (RTA575), and $725{ }^{\circ} \mathrm{C}$ (RTA725) for $60 \mathrm{~s}$ after deposition. More details on the SCS synthesis of doped $\mathrm{ZnO}$ columnar films are presented in our previous works. ${ }^{16-21}$

Silver nanoparticles (Ag NPs) were deposited onto the $\mathrm{ZnO}: \mathrm{Ag}$ sensor layers with different densities via the gas-phase physical vapor deposition process based on a homemade ${ }^{22,23}$ Haberland-type ${ }^{24}$ gas aggregation cluster source and unipolar direct current (DC) planar magnetron sputtering. The target (Ag, Kurt J. Lesker, 99.99\%, $5 \mathrm{~cm}$ diameter) was mounted onto a DC planar magnetron source (Thin Film Consulting, ION'X-2UHV). The base pressure of the HV deposition system prior to every deposition was below $10^{-4} \mathrm{~Pa}$, using a two-stage pumping system (turbo molecular pump, Pfeiffer Vacuum, TMU 262; dry scroll pump, Agilent Technologies, SH-110). For the nanoparticle deposition, a flow of Ar (48SCCM, purity of 99.999\%) was supplied at the gas inlet close to the target (gas regulating valve, Pfeiffer, EVR116 with attached hot ion cathode IMR 285), resulting in a pressure of typically $136 \mathrm{~Pa}$ during deposition. The DC power of $40 \mathrm{~W}$ was supplied by Advanced Energy, MDX 500. Prior to the deposition of nanoparticles, the $\mathrm{Ag}$ target was cleaned, and the nanoparticle growth was achieved by sputtering with closed shutter for a sufficient time (at least $30 \mathrm{~s}$ ) to reach stable deposition conditions. After deposition, the samples were subjected to thermal annealing in air at $350{ }^{\circ} \mathrm{C}$ for $1 \mathrm{~h}$.

The methodology details for the fabrication of the sensor structures are presented in previous works, ${ }^{19,25}$ and the measurement of the gas sensing properties are presented in our publications. ${ }^{18,26,27}$ The electrical measurements were performed using a Keithley 2400 sourcemeter with two-wire configuration through the LabVIEW software (National Instruments). ${ }^{27}$ To form contacts, a thin layer of gold $(\mathrm{Au}, \sim 170 \mathrm{~nm})$ was sputtered on the surface of columnar films. The gap between contacts is $\sim 1 \mathrm{~mm}$. The final structure of the device is $\mathrm{Au} / \mathrm{AgNPs} / \mathrm{ZnO}: \mathrm{Ag} / \mathrm{Au}$.

2.2. Characterization of Materials. The $\mathrm{ZnO}: \mathrm{Ag} / \mathrm{AgNP}$ nanocomposite as well as its constituents, the $\mathrm{ZnO}: \mathrm{Ag}$ base layer, and the deposited AgNP were investigated by X-ray photoelectron spectroscopy (XPS, Omicron NanoTechnology GmbH). The X-ray source was operated with an $\mathrm{Al}$ anode at a power of $240 \mathrm{~W}$. All recorded spectra were charge-referenced by using aliphatic carbon $\mathrm{C} 1 \mathrm{~s}$ at 285.0 $\mathrm{eV}$ using the software CasaXPS (version 2.3.16). (S)TEM analyses were performed using FEI Tecnai F30 G2 (FEG, $300 \mathrm{kV}$ ) equipped with a $\mathrm{Si}(\mathrm{Li})$ EDX detector (EDAX system).

2.3. Computational Details. We employed the Vienna ab initio simulation package (VASP), ${ }^{28}$ which solves the Kohn-Sham equations of the density functional theory (DFT) in periodic conditions to simulate all geometries and energies. ${ }^{29}$ All the calculations were spin-polarized, and the generalized gradient approximation (GGA) with the Perdew-Burke-Ernzerhof (PBE) ${ }^{30}$ was adopted as the density functional. The semiempirical method of Grimme with the Becke-Johnson damping (DFT-D3-(BJ)) ${ }^{31}$ was considered to evaluate the long-range dispersion interactions. The $d$ electrons of $\mathrm{Zn}$ and $\mathrm{Ag}$ were corrected using the Dudarev approach, ${ }^{32}$ in the DFT $+U^{33}$ scheme, as implemented in the VASP software. Note that the $U$ considered in this work corresponds to the effective Hubbard $U_{\text {eff }}=U-J$, where the exchange parameter $J$ is equal to zero. We chose a $U_{\text {eff }}$ value of $6.0 \mathrm{eV}$ for both $\mathrm{Ag}^{34}$ and $\mathrm{Zn}^{27}$ atoms.

The electrons in the $4 \mathrm{~d} 5 \mathrm{~s}$ orbitals of $\mathrm{Ag}, 3 \mathrm{~d} 4 \mathrm{~s}$ of $\mathrm{Zn}, 2 \mathrm{~s} 2 \mathrm{p}$ of $\mathrm{O}$ as well as $\mathrm{C}$, and $1 \mathrm{~s}$ of $\mathrm{H}$ were treated as valence electrons. The projected augmented wave method (PAW) ${ }^{35}$ was employed to describe the interaction between the atomic frozen core states and the valence electrons. The plane-wave basis set expansion was calculated by affixing the kinetic energy cutoff at $400 \mathrm{eV}$. We used the conjugate gradient technique with an ionic convergence criterion of $0.01 \mathrm{eV} / \AA$ for all geometry optimizations. We sampled the reciprocal space by adopting a $\Gamma$-centered $4 \times 4 \times 2$ and $1 \times 1 \times 1$ mesh of $k$-points for the $\mathrm{ZnO}$ bulk and $\mathrm{ZnO}(0001)$ surface, respectively. We also adopted a $1 \times 1 \times 1$ mesh of $k$-points for the optimization of the molecules in the gas phase where each molecule was positioned in the center of a large box $\left(20 \times 21 \times 22 \AA^{3}\right)$ to avoid lateral interactions.

We considered the wurtzite structure of the $\mathrm{ZnO}$ bulk, which belongs to the space group $P 6_{3} m c$ (no. 186). We optimized and described the $\mathrm{ZnO}$ bulk in our previous investigation. ${ }^{20}$ We generated 
the $\mathrm{ZnO}(0001)$ surface from the bulk using the METADISE ${ }^{36}$ code, which takes into account the periodicity of the planes parallel to the surface and the atomic charges. To quench the dipole moment of the $\mathrm{ZnO}(0001)$ surface, we removed $\mathrm{Zn}$ atoms from the upper surface layer, similarly to previous investigations. ${ }^{37}$

Our $\mathrm{ZnO}(0001)$ surface is modeled by a $1 \times 1$ supercell, that is, containing two infinite surfaces at either side of the slab. A $20 \AA$ of vacuum was added in the $z$ direction to avoid interaction between neighboring cells. The $\mathrm{ZnO}(0001)$ slab contains four atomic layers (30 atoms) where the top two layers were allowed to relax during geometry optimization, and the bottom two layers were kept fixed at their equilibrium bulk position. The surface area is $35.49 \AA^{2}$ for the 1 $\times 1$ supercell. We expanded our supercell to $2 \times 1$ and $2 \times 2$ slabs for $\mathrm{Ag}$ doping and $\mathrm{Ag}_{8}$ clusters adsorption as well as the molecule adsorptions, respectively. The $2 \times 1$ slab has a surface area of $70.98 \AA^{2}$ and contains 60 atoms, while the $2 \times 2$ slab has a surface area of $141.97 \AA^{2}$ and contains 120 atoms.

To evaluate the interaction between the $\mathrm{Ag}_{8}$ cluster and the $\mathrm{Ag}$ doped $\mathrm{ZnO}(0001)$ surface, we calculated the clustering energy per $\mathrm{Ag}$ atom $\left(E_{\text {clus }}\right)($ eq 1$)$

$$
E_{\text {clus }}=\frac{E_{\mathrm{Ag}_{8} / \text { surf }}-\left(E_{\text {surf }}+8 E_{\mathrm{Ag}}\right)}{8}
$$

where $E_{\mathrm{Ag} / \text { surf }} E_{\text {surf }}$ and $E_{\mathrm{Ag}}$ are the energies of the doped slab with the $\mathrm{Ag}_{8}$ cluster, the clean doped oxide surface, and the $\mathrm{Ag}$ metal atom in the bulk, respectively, and 8 is the number of adsorbed $\mathrm{Ag}$ atoms. A positive clustering energy proves that the $\mathrm{Ag}$ atoms prefer to aggregate rather than spread over the surface, while a negative clustering energy indicates that the $\mathrm{Ag}$ atoms tend to wet the surface.

To describe the interaction of the molecules with the fully modified oxide surface, that is, Ag-doped and decorated with the $\mathrm{Ag}_{8}$ cluster, we calculated the binding energy as (eq 2)

$$
E_{\mathrm{B}}=E_{\text {molecule-surface }}-\left(E_{\text {surface }}+E_{\text {molecule }}\right)
$$

where $E_{\text {molecule-surface }}$ is the energy of the fully modified surface and the adsorbed molecule, while $E_{\text {surface }}$ and $E_{\text {molecule }}$ are the energies of the surface without the molecule and the isolated molecule, respectively. A positive binding energy is the consequence of an unfavorable endothermic adsorption, while a negative value indicates a favorable exothermic molecular adsorption.

We carried out the charge analysis of the system using the Bader atoms-in-molecules methodology as implemented in the Henkelman algorithm. ${ }^{38}$

\section{RESULTS AND DISCUSSION}

3.1. Morphological Characterization of Nanomaterials. Figure $1 \mathrm{a}-\mathrm{d}$ shows the scanning electron microscopy (SEM) images of nanocolumnar $\mathrm{ZnO}: \mathrm{Ag}$ films after rapid thermal annealing (RTA) at $575{ }^{\circ} \mathrm{C}$ with different $\mathrm{Ag}$ nominal concentrations (in wt \%). All samples of pure and Ag-doped $\mathrm{ZnO}$ are composed of closely packed grains/columns forming thin films (see Figure S1). The column radius of the undoped samples lies between $100-250 \mathrm{~nm}$, which decreases to $25-120$ $\mathrm{nm}$ and 50-150 nm after doping with $\mathrm{Ag}$ at 0.50 and $0.95 \mathrm{wt}$ $\%$, respectively (see Figure $1 \mathrm{a}-\mathrm{c}$ ). However, a further increase in the $\mathrm{Ag}$ content to $1.3 \mathrm{wt} \%$ favors larger column radius of $70-220 \mathrm{~nm}$ (see Figure 1d). The column size histogram of $\mathrm{ZnO}: \mathrm{Ag}$ with different $\mathrm{Ag}$ contents as a function of the RTA temperature is presented in Figure S2, showing the changes in column diameter. ${ }^{18,19}$ Figure $1 \mathrm{e}-\mathrm{h}$ and Figure S3 show the SEM images of Ag NP-functionalized $\mathrm{ZnO}$ :Ag samples, where the nanoscopic particles with different densities on the surface of the $\mathrm{ZnO}: \mathrm{Ag}$ columns can be observed. In both cases, the NPs have a diameter of $6-12 \mathrm{~nm}$ and are well distributed on the surface of the $\mathrm{ZnO}: \mathrm{Ag}$ columns/grains without a visible formation of percolating paths between NPs. The samples with

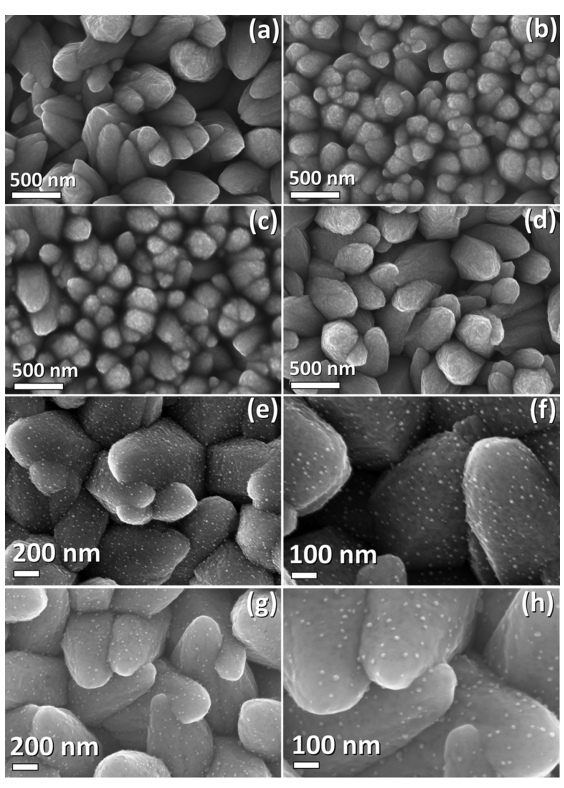

Figure 1. SEM images of columnar $\mathrm{ZnO}: \mathrm{Ag}$ films after rapid annealing RTA at $575^{\circ} \mathrm{C}$ for 60 s with: (a) 0.00, (b) 0.50, (c) 0.95, and (d) 1.30 wt \% Ag content. SEM images of Ag-functionalized columnar $\mathrm{ZnO}: \mathrm{Ag}$ films: (e, f) $\mathrm{Ag}(1) / \mathrm{ZnO}: \mathrm{Ag}$ and (g, h) $\mathrm{Ag}(2) /$ $\mathrm{ZnO}: \mathrm{Ag}$.

lower density of Ag NPs $\left(\sim 0.5 \times 10^{9} \mathrm{~cm}^{-2}\right.$; see Figure $\left.1 \mathrm{e}, \mathrm{f}\right)$ will be designated further as $\mathrm{Ag}(1) / \mathrm{ZnO}: \mathrm{Ag}$, while samples with higher density of Ag NPs $\left(\sim 0.8 \times 10^{9} \mathrm{~cm}^{-2}\right.$; see Figure $1 \mathrm{~g}, \mathrm{~h})$ will be designated further as $\mathrm{Ag}(2) / \mathrm{ZnO}: \mathrm{Ag}$.

3.2. Structural Characterization of Materials. The crystal structure and preferential orientation of the $\mathrm{ZnO}: \mathrm{Ag}$ columnar films on the glass substrates were studied by X-ray diffraction $(\mathrm{XRD})$. Figure 2a displays the XRD patterns for the pure and Ag-doped samples deposited using the synthesis from
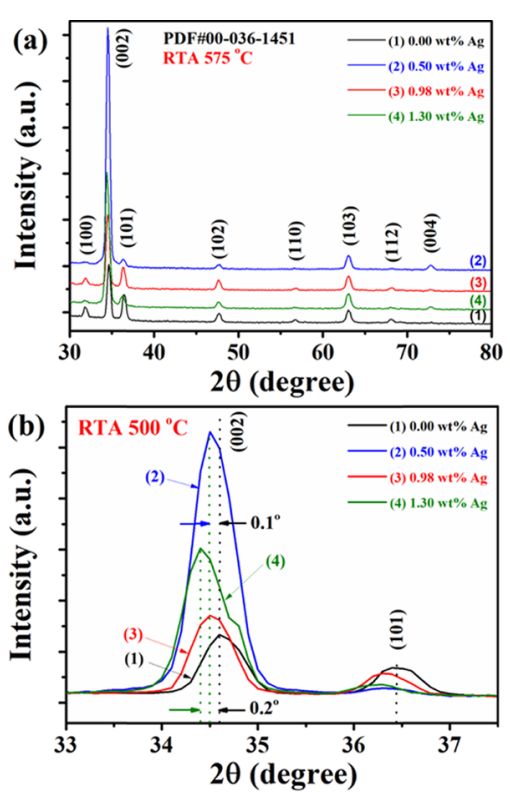

Figure 2. (a) XRD patterns of the columnar $\mathrm{ZnO}$ and $\mathrm{ZnO}: \mathrm{Ag}$ films subjected to RTA at $575{ }^{\circ} \mathrm{C}$ for $60 \mathrm{~s}$ with different Ag contents. (b) Enlargement of the XRD pattern in the region between $2 \theta=33$ and $37.5^{\circ}$ exhibit reflections corresponding to the (002) and (101) planes for the samples with different $\mathrm{Ag}$ concentrations. 
chemical solution (SCS) method and subjected to the RTA at $575{ }^{\circ} \mathrm{C}$ for $60 \mathrm{~s}$. The relatively low background intensity demonstrates good crystallinity of the $\mathrm{ZnO}$ samples, which can be assigned to the hexagonal wurtzite structure with space group $\mathrm{P}_{3} m c$ (no. 186). Figure 2a illustrates that the strongest detected $(h k l)$ reflections are at expected $2 \theta$ values and correspond to the (100), (002), (101), (102), (110), (103), (112), and (004) Miller planes. We found an increase in the crystallinity by adding silver nitrate to the zinc complex solution during preparation of the $\mathrm{ZnO}$ : Ag film. A sharp (002) reflection at $2 \theta \approx 34.6^{\circ}$ with the highest observed intensity for the undoped $\mathrm{ZnO}$ shows a preferential growth along the $c$ axis normal to the glass substrate. ${ }^{18}$

To gain insight into the effect of the various $\mathrm{Ag}$ concentrations on the crystallinity of the $\mathrm{ZnO}: \mathrm{Ag}$ columnar films, we monitored the intensity of the (002) and (101) reflections (see Figure $2 \mathrm{~b}$ ). The XRD patterns indicate a shift to lower scattering angles $\left(2 \theta, \sim 0.1^{\circ}\right)$ for the samples with $\sim 0.50$ wt $\%$ Ag (curve 2) and $\sim 0.95$ wt $\%$ Ag (curve 3), while the highest Ag content of $\sim 1.3 \mathrm{wt} \%$ (curve 4 ) induces a larger $2 \theta$ shift $\left(\sim 0.2^{\circ}\right)$. It is the result of either the Ag ion interstitial incorporation into or $\mathrm{Zn}^{2+}$ substitution within the $\mathrm{ZnO}$ lattice $^{39}$ due to the 1.7 times larger ionic radii of $\mathrm{Ag}^{+}$with respect to $\mathrm{Zn}^{2+} \cdot{ }^{40}$ A similar lattice deformation was also observed for the Ag-doped $\mathrm{ZnO}$ thin films, ${ }^{40}$ where the value of the $2 \theta$ angle shift increases with the Ag concentration.

Figure $3 \mathrm{a}$ depicts the high-resolution transmission electron microscopy (HRTEM) micrographs and fast Fourier transform

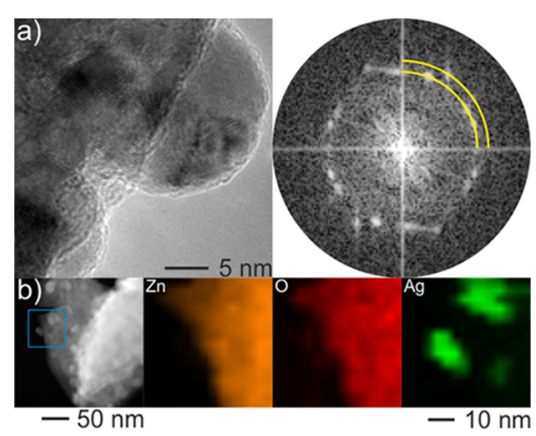

Figure 3. (a) HRTEM and FFT of one Ag nanoparticle attached to the $\mathrm{ZnO}$ surface. (b) High-angle annular dark-field (HAADF)-STEM and EDX elemental maps of the marked region.

(FFT) of nanoparticles attached to the surface of the single crystalline $\mathrm{ZnO}$ columnar matrix. The nanoparticle exhibited $d$ spacing values of 2.30 and $2.04 \AA$ corresponding to the crystal structure of cubic Ag. A clear epitaxial relation between the $\mathrm{Ag}$ nanoparticles and the $\mathrm{ZnO}$ matrix could not be observed. Bright atomic number-dependent contrast via high-angle annular dark-field scanning TEM (HAADF-STEM) exhibits Ag particles of 5-10 nm. The energy-dispersive X-ray (EDX) elemental maps verify the presence of nonoxidized Ag NPs attached to the $\mathrm{ZnO}$ columnar matrix surface.

3.3. Micro-Raman Characterization. The Raman spectra were measured at room temperature in the range between 60 and $1200 \mathrm{~cm}^{-1}$ to identify the influence of the $\mathrm{Ag}$ dopant on the columnar $\mathrm{ZnO}: \mathrm{Ag}$ films (see Figure 4). Group theory predicts the optical phonons at the $\Gamma$ point of the Brillouin zone and has the following representation ${ }^{41}$

$$
\Gamma_{\text {opt }}=1 A_{1}+1 E_{1}+2 E_{2}+2 B_{1}
$$

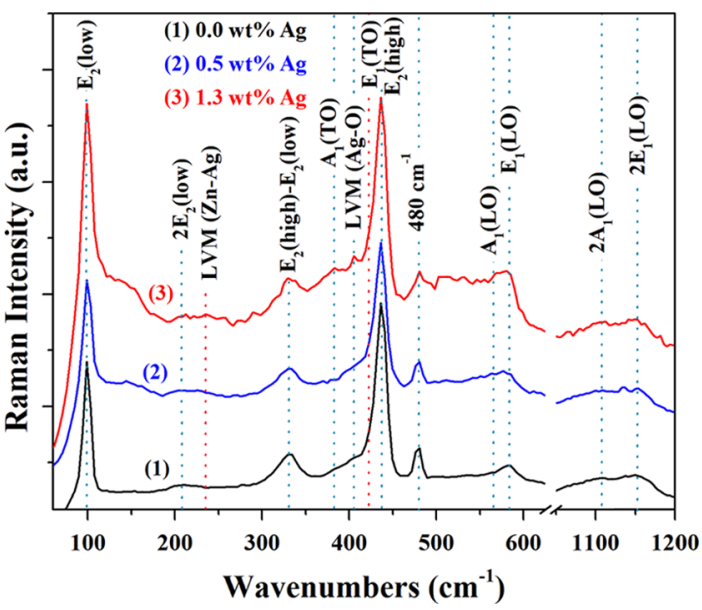

Figure 4. Raman spectra of columnar $\mathrm{ZnO}: \mathrm{Ag}$ films with different $\mathrm{Ag}$ nominal contents.

where $A_{1}, E_{1}$, and $E_{2}$ modes are Raman active phonons while $A_{1}$ and $E_{1}$ are also infrared-active. ${ }^{41}$ The $A_{1}$ phonon vibrations are polarized parallel to the $c$ axis while the $E_{1}$ phonon vibrations are perpendicularly polarized to the $c$ axis. ${ }^{41}$

Figure 4 shows the room temperature Raman spectra of the columnar $\mathrm{ZnO}: \mathrm{Ag}$ films with $\mathrm{Ag}$ nominal content in the spectral range between 60 and $1200 \mathrm{~cm}^{-1}$. For all samples, we observed peaks at around: (i) $99 \mathrm{~cm}^{-1}$, which corresponds to the $E_{2}$ (low) fundamental phonon mode of $\mathrm{ZnO}$ with wurtzite structure and is associated with the heavy $\mathrm{Zn}$ sublattice; ${ }^{42}$ (ii) $204 \mathrm{~cm}^{-1}$, which corresponds to the $2 E_{2}$ (low) second-order phonon mode; (iii) $330 \mathrm{~cm}^{-1}$, which is assigned to the $E_{2}$ (high) $-E_{2}$ (low) multiphonon scattering; (iv) $383 \mathrm{~cm}^{-1}$, which corresponds to the $A_{1}(\mathrm{TO})$ phonon mode; (v) 418 $\mathrm{cm}^{-1}$, which corresponds to the $E_{1}$ (TO) phonon mode; (vi) $436 \mathrm{~cm}^{-1}$, which corresponds to the $E_{2}$ (high) phonon mode and involves only the oxygen atoms; ${ }^{42}$ (vii) $480 \mathrm{~cm}^{-1}$, which corresponds to the interfacial surface phonon mode; (viii) 567 $\mathrm{cm}^{-1}$, which is assigned to the $A_{1}(\mathrm{LO})$; (ix) $581 \mathrm{~cm}^{-1}$, which correspond to the $E_{1}(\mathrm{LO})$ phonon mode that is commonly assigned to the zinc interstitials and oxygen vacancies in $\mathrm{ZnO}^{42}$ and $(\mathrm{x}) 1104 \mathrm{~cm}^{-1}$ as well as $1149 \mathrm{~cm}^{-1}$, which correspond to the multiple phonon process of the $A_{1}(\mathrm{LO})$ and $E_{1}(\mathrm{LO})$, respectively. ${ }^{42}$

The $E_{2}$ (low) and $E_{2}$ (high) phonon modes of the Raman spectra are characteristics of a perfect $\mathrm{ZnO}$ crystal, which becomes broader by the addition of Ag. ${ }^{18}$ The presence of a Ag dopant also induces an intensity change of $A_{1}(\mathrm{TO})$ and $A_{1}(\mathrm{LO})$ polar branches, the $E_{1}(\mathrm{LO})$ phonon mode, and the broad peak at $144 \mathrm{~cm}^{-1}$, which appears due to lattice vibration. ${ }^{42}$ Thus, the Ag incorporation into the columnar $\mathrm{ZnO}$ films as well as the TA or RTA treatment at relatively higher temperatures decrease the crystallinity and increase the concentration of the zinc interstitials and oxygen vacancies. ${ }^{42}$

Figure 4 also shows the broadening and intensity changes of the peaks within the range between 500 and $560 \mathrm{~cm}^{-1}$ and the $A_{1}$ (LO) phonon mode for the highly doped sample with 1.30 wt \% Ag (curve (3)). This is the consequence of the defects based on silver incorporation as well as Ag segregation at the crystallite interface. The same peaks have been observed previously for Ag-doped $\mathrm{ZnO}$ microspheres because of the silver segregation around the grain boundaries and other localized disordered domains ${ }^{43}$ and for $\mathrm{Mn}$-doped $\mathrm{ZnO}$ nanorods due to the defect-activated mode $\left(M_{\mathrm{D}}\right)$ that 

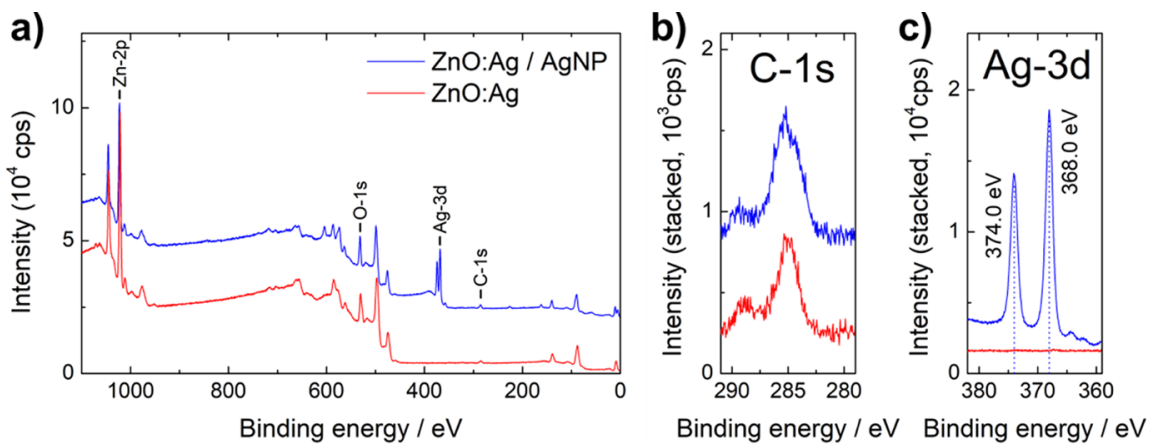

Figure 5. XPS spectra of the $\mathrm{ZnO}: \mathrm{Ag}$ reference layer (red, bottom line) and the $\mathrm{ZnO}: \mathrm{Ag}$ nanocomposite decorated with Ag NPs (blue, top line): (a) spectra in the $0-1100 \mathrm{eV}$ region, (b) high-resolution spectra of the $\mathrm{C} 1 \mathrm{~s}$ line, and (c) high-resolution spectra of the Ag $3 \mathrm{~d}$ lines.

represent intrinsic host lattice defects. ${ }^{44}$ For both the undoped and Ag-doped columnar $\mathrm{ZnO}$ films, we observed an additional mode at $480 \mathrm{~cm}^{-1}$ due to an interfacial surface phonon mode. $^{45}$ This phonon mode does not depend on the presence or nature of the dopant atom and has also been reported for the Ag-doped $\mathrm{ZnO}$ microspheres. ${ }^{45}$

The Raman mapping technique was applied to investigate the spatial distribution of crystallinity and defects in the wurtzite-based $\mathrm{ZnO}$ :Ag columnar films containing different $\mathrm{Ag}$ concentrations. Figure S4a-d shows the Raman mapping for the $E_{2}$ high band integrated between 420 and $450 \mathrm{~cm}^{-1}$ for the $\mathrm{ZnO}$ :Ag samples and produced using RTA at $575{ }^{\circ} \mathrm{C}$ for $60 \mathrm{~s}$. The Raman scattering experiments for both the undoped and doped columnar films show that their crystallinity is relatively uniform, indicating that the doping with $\mathrm{Ag}$ atoms does not affect the structural stability of the matrix support. Figure S4e shows the deconvolution using a Gaussian fitting of the 300$460 \mathrm{~cm}^{-1}$ Raman spectroscopy range for the sample with 1.3 wt $\%$ Ag showing the additional local vibrational modes.

3.4. X-ray Photoemission Spectroscopy (XPS). The Xray photoemission spectra (XPS) of the $\mathrm{Ag} / \mathrm{ZnO}: \mathrm{Ag}$ nanocomposite (blue line) and the undecorated $\mathrm{ZnO}: \mathrm{Ag}$ reference thin film (red line) are shown in Figure 5a. The spectra were charge-referenced using the $\mathrm{C} 1 \mathrm{~s}$ line of aliphatic carbon, as depicted in Figure 5b. In both the $\mathrm{Ag} / \mathrm{ZnO}: \mathrm{Ag}$ nanocomposite and undecorated $\mathrm{ZnO}: \mathrm{Ag}$ thin films, we found evidence of $\mathrm{C}$, $\mathrm{O}$, and $\mathrm{Zn}$. The occurrence of $\mathrm{C}$ is attributed to atmospheric contamination of the thin film surface, originating from contact with ambient air during handling and transportation of the samples. As expected, no Ag was detected in the undecorated thin film since the dopant concentration is below the detection limit of the XPS instrument. For the Ag NP decorated $\mathrm{ZnO}: \mathrm{Ag}$ thin film, we observed a well-resolved peak doublet at 368.0 and $374.0 \mathrm{eV}$, which agrees with the position of the $\mathrm{Ag} 3 \mathrm{~d}_{5 / 2}$ and $\mathrm{Ag} 3 \mathrm{~d}_{3 / 2}$ lines, respectively (see Figure 5c). ${ }^{46}$ Typically, the binding energy of $\sim 368.2 \mathrm{eV}$ is attributed to metallic Ag, whereas the silver oxides are slightly shifted to lower binding energies of $\sim 367.9 \mathrm{eV}$ for $\mathrm{Ag}_{2} \mathrm{O}$ and $367.6 \mathrm{eV}$ for $\mathrm{AgO}$. $^{46}$ Given the small chemical shifts for $\mathrm{Ag}^{+}$and $\mathrm{Ag}^{2+}$ with regard to metallic $\mathrm{Ag}$, we confirmed the presence of elemental $\mathrm{Ag}$ forming the Ag NPs using transmission electron microscopy (TEM).

To investigate the introduction of the Ag dopant, we produced an undecorated $\mathrm{ZnO}: \mathrm{Ag}$ film with a silver concentration approximately 10 -fold the typical value used within this work. For the Ag 3d lines of this thin film, the XPS high-resolution spectrum depicted in Figure S5 was recorded with high pass energy to maximize the signal strength. The observed $\mathrm{Ag} 3 \mathrm{~d}_{3 / 2}$ and $\mathrm{Ag} 3 \mathrm{~d}_{1 / 2}$ peaks prove the successful incorporation of $\mathrm{Ag}$ dopant into the columnar film. ${ }^{46} \mathrm{We}$ also performed XPS measurements for the $\mathrm{Ag} / \mathrm{ZnO}: \mathrm{Ag}$ sample before and after heat treatment at $350{ }^{\circ} \mathrm{C}$ for $1 \mathrm{~h}$ (see Figure $\mathrm{S6}$ ). For the annealed sample, the $\mathrm{Ag} 3 \mathrm{~d}$ lines match perfectly the electron binding energy of the same samples, which suggests that the thermal treatment at this temperature and duration has a negligible effect on the oxidation state of the $\mathrm{Ag}$ NPs.

3.5. Electrical Properties Characterization. The electrical properties of the $\mathrm{ZnO}: \mathrm{Ag}$ nanocolumnar films strongly influence the gas sensing behavior toward VOCs. ${ }^{25}$ Figure $6 \mathrm{a}$ shows the resistivity at $300 \mathrm{~K}$ of the columnar Ag-doped $\mathrm{ZnO}$ films as a function of the $\mathrm{Ag}$ concentration. Note that we treated the samples using different RTA temperatures for $60 \mathrm{~s}$. The electrical resistivity was calculated from the linear
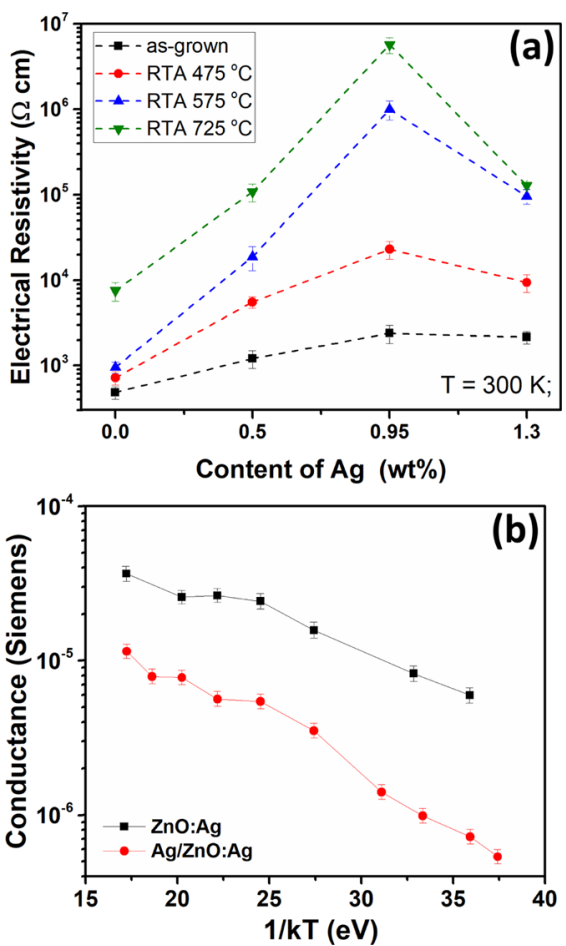

Figure 6. (a) Electrical resistivity of the $\mathrm{ZnO}$ :Ag columnar films at $300 \mathrm{~K}$ as a function of the Ag nominal content. RTA temperature is indicated. (b) Arrhenius plot for the columnar $\mathrm{ZnO}: \mathrm{Ag}$ and $\mathrm{Ag}$ functionalized $\mathrm{ZnO}: \mathrm{Ag}(\mathrm{Ag} / \mathrm{ZnO}: \mathrm{Ag})$ films with $0.50 \mathrm{wt} \% \mathrm{Ag}$ and treated using RTA at $725^{\circ} \mathrm{C}$ during $60 \mathrm{~s}$. 

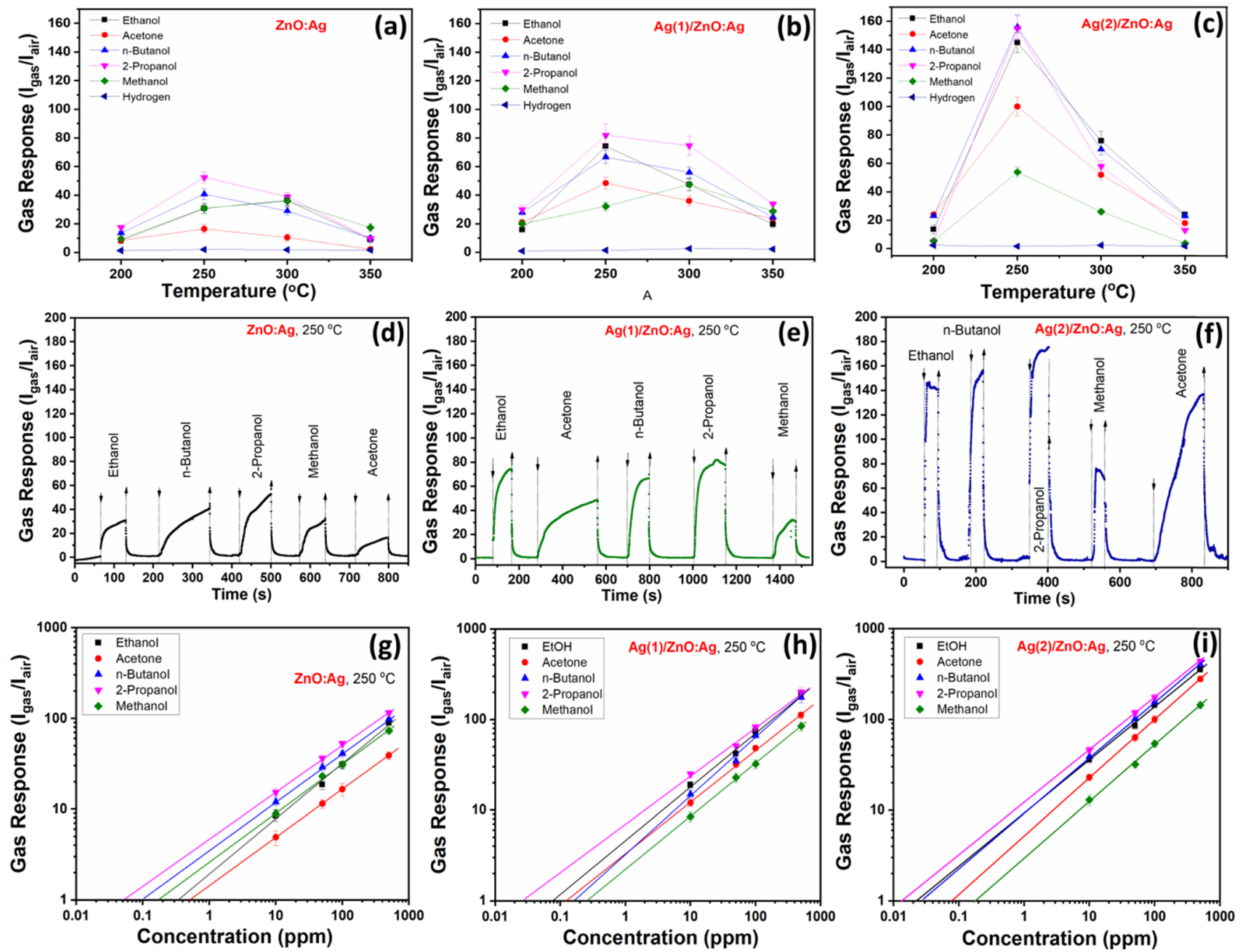

Figure 7. Gas response to $1000 \mathrm{ppm}$ of $\mathrm{H}_{2}$ gas and $100 \mathrm{ppm}$ of different vapors of volatile organic compounds as a function of the operating temperature for: (a) $\mathrm{ZnO}: \mathrm{Ag}$, (b) $\mathrm{Ag}(1) / \mathrm{ZnO}: \mathrm{Ag}$, and (c) $\mathrm{Ag}(2) / \mathrm{ZnO}: \mathrm{Ag}$ columnar films. Dynamic response to 100 ppm of VOC vapors (at OPT of $250{ }^{\circ} \mathrm{C}$ ) for: (d) $\mathrm{ZnO}: \mathrm{Ag}$, (e) $\mathrm{Ag}(1) / \mathrm{ZnO}: \mathrm{Ag}$, and (f) $\mathrm{Ag}(2) / \mathrm{ZnO}: \mathrm{Ag}$ columnar film-based sensor structures. The gas response versus concentration of VOC vapors for: $(\mathrm{g}) \mathrm{ZnO}: \mathrm{Ag},(\mathrm{h}) \mathrm{Ag}(1) / \mathrm{ZnO}: \mathrm{Ag}$, and (i) $\mathrm{Ag}(2) / \mathrm{ZnO}: \mathrm{Ag}$ columnar films.

current-voltage characteristics (meaning ohmic behavior, not shown) of the $\mathrm{ZnO}: \mathrm{Ag}$ structures enclosed by sputtered $\mathrm{Au}$ contact pads using two-wire configuration (see Experimental Section or previous publications). ${ }^{16-18}$

We observed that the electrical resistivities of both $\mathrm{ZnO}$ and $\mathrm{ZnO}: \mathrm{Ag}$ nanocolumnar films increased with the RTA temperature. The elevated RTA temperatures lower the carrier concentration of $\mathrm{Zn}$ interstitials, which are lost by evaporation. This finding is supported by previous evidence where postannealing treatments were used to tune the structural, electrical, and optical properties of materials. ${ }^{46}$

The electrical resistivity is also significantly modified by the $\mathrm{Ag}$ content in the $\mathrm{ZnO}: \mathrm{Ag}$ columnar films (see Figure 6a). Silver is an amphoteric dopant of $\mathrm{ZnO}$ where it acts as an acceptor on substitutional $\mathrm{Zn}^{2+}$ sites $\left(\mathrm{Ag}_{\mathrm{Zn}}^{\prime}\right)$ or as a donor on the interstitial sites $\left(\mathrm{Ag}_{i}^{*}\right){ }^{47}$ By increasing the silver concentration up to $0.95 \mathrm{wt} \%$, the electrical resistivity of the films sharply increased. At this relatively high concentration, $\mathrm{Ag}^{+}$behaves as an acceptor as it prefers to occupy substitutionally the $\mathrm{Zn}^{2+}$ sites, as deduced from Raman analyses and supported by XRD (see Figures $2 b$ and $4 b$ ). Moreover, positively charged oxygen vacancies $\left(V_{\mathrm{O}}^{\bullet \bullet}\right)$ that act as acceptors are formed to maintain charge neutrality. ${ }^{47} \mathrm{By}$ increasing the $\mathrm{Ag}$ content further, no reliable p-type behavior was observed in our case. We found that the Ag atoms prefer to occupy the interstitial sites $\left(\mathrm{Ag}_{i}^{*}\right)$ at high concentration of the dopant where they form neutral defects or segregate at the grain boundaries. ${ }^{47}$ The large content of electron-rich dopant atoms leads to the reduction in the electrical resistivity of the columnar Ag-doped $\mathrm{ZnO}$ films (see Figure 6a). ${ }^{47}$ The competition of the $\mathrm{Ag}^{+}$ions for the $\mathrm{Zn}^{2+}$ or interstitial sites can be rationalized in terms of the relative ionic radii of these ions. ${ }^{40}$ It has been suggested that the interstitial holes become the most favorable for the dopant atoms once the substitutional positions are saturated. ${ }^{47}$ On the other hand, the reduction in resistivity at $\mathrm{Ag}$ contents $>0.95$ wt \% can also be the consequence of the larger grain size detected through the SEM and XRD experiments. The reduced grain boundary density of larger particles results in the weakening of the intergrain boundary scattering and the increase in the carrier lifetime and mobility. ${ }^{47}$

Figure $6 \mathrm{~b}$ shows the Arrhenius plot of conductance as a function of $1 / \mathrm{kT}$ for both the $\mathrm{ZnO}: \mathrm{Ag}$ and $\mathrm{Ag}$-functionalized $\mathrm{ZnO}: \mathrm{Ag}$ columnar films with 0.50 wt \% Ag obtained using 
Table 1. VOC Sensors Based on Metal Oxides Modified/Decorated with Different Noble Metals

\begin{tabular}{|c|c|c|c|c|c|}
\hline sensing material & VOC conc. (ppm) & $\begin{array}{c}\text { gas response }\left(I_{\text {gas }} / I_{\text {air }}\right) \text { or } \\
\left(R_{\text {air }} / R_{\text {gas }}\right)\end{array}$ & $\begin{array}{l}\text { operating temperature } \\
\left({ }^{\circ} \mathrm{C}\right)\end{array}$ & $\begin{array}{l}\text { response time } \\
(\mathrm{s})\end{array}$ & $\begin{array}{l}\text { recovery time } \\
\text { (s) }\end{array}$ \\
\hline $\mathrm{Ag}-\mathrm{ZnO}$ films ${ }^{64}$ & ethanol EtOH, 2000 & $\sim 2$ & 225 & 5 & \\
\hline Ag-doped $\mathrm{ZnO}$ films ${ }^{39}$ & ethanol EtOH, 100 & $\sim 15$ & 260 & & \\
\hline Ag-doped $\mathrm{ZnO}$ nanorods ${ }^{65}$ & ethanol EtOH, 100 & 19.4 & 332 & & \\
\hline $\mathrm{Ag} / \mathrm{ZnO}$ nanorods ${ }^{66}$ & ethanol EtOH, 100 & 36.52 & 360 & 50 & 28 \\
\hline $\mathrm{ZnO}-\mathrm{Ag}$ hybrids ${ }^{67}$ & ethanol EtOH, 100 & 101.8 & 370 & $\sim 15$ & $\sim 20$ \\
\hline \multirow[t]{3}{*}{$\mathrm{Ag}-\mathrm{ZnO}$ nanorods ${ }^{68}$} & ethanol EtOH, 50 & 34.8 & & & \\
\hline & acetone, 50 & 25 & 280 & & \\
\hline & methanol, 50 & 14.5 & & & \\
\hline \multirow[t]{4}{*}{ Ag-loaded $\mathrm{ZnO}^{69}$} & ethanol EtOH, 100 & $\sim 75$ & & & \\
\hline & acetone, 100 & $\sim 30$ & 240 & & \\
\hline & isopropanol, 100 & $\sim 68$ & & & \\
\hline & methanol, 100 & $\sim 55$ & & & \\
\hline $\begin{array}{l}\text { Ag-doped } \mathrm{ZnO}_{70}-\mathrm{SnO}_{2} \text { hollow } \\
\text { nanofibers }\end{array}$ & ethanol EtOH, 1 & 7.6 & 200 & 5 & 5 \\
\hline $\mathrm{Ag}-\left(\mathrm{TiO}_{2} / \mathrm{SnO}_{2}\right)^{56}$ & ethanol EtOH, 50 & 53 & 275 & 3.5 & 7 \\
\hline \multirow[t]{5}{*}{$\mathrm{ZnO}: \mathrm{Ag}$ columnar films (this work) } & ethanol EtOH, 100 & 31 & & & \\
\hline & acetone, 100 & 16.5 & & & \\
\hline & 2-propanol, 100 & 52.5 & 250 & & \\
\hline & $n$-butanol, 100 & 41 & & & \\
\hline & methanol, 100 & 31 & & & \\
\hline \multirow{5}{*}{$\begin{array}{l}\mathrm{Ag}(2) / \mathrm{ZnO}: \mathrm{Ag} \text { columnar films(this } \\
\text { work) }\end{array}$} & ethanol EtOH, 100 & $145 \pm 6.2$ & & & \\
\hline & acetone, 100 & $156 \pm 5.8$ & & & \\
\hline & 2-propanol, 100 & & 250 & & \\
\hline & $n$-butanol, 100 & $155 \pm 6.5$ & & & \\
\hline & methanol, 100 & $54 \pm 2.1$ & & & \\
\hline
\end{tabular}

RTA at $725^{\circ} \mathrm{C}$ during $60 \mathrm{~s}$. For both samples, we observed a double-valued activation energy in which associated conductivity can be expressed as ${ }^{48}$

$$
\sigma=\sigma_{1} \exp \left(-E_{\mathrm{a} 1} / k T\right)+\sigma_{2} \exp \left(-E_{\mathrm{a} 2} / k T\right)
$$

where $E_{\mathrm{a} 1}$ is the activation energy for the band conduction, $E_{\mathrm{a} 2}$ is the activation energy for the nearest neighbor hopping conduction, $k$ is the Boltzmann constant, $\sigma_{1}$ and $\sigma_{2}$ are the preexponential factors, and $T$ is the absolute temperature. ${ }^{48}$ The $E_{\mathrm{a} 1}$ values of 52.9 and $78.6 \mathrm{meV}$ were obtained for $\mathrm{ZnO}: \mathrm{Ag}$ and $\mathrm{Ag} / \mathrm{ZnO}: \mathrm{Ag}$, respectively, which are consistent with other results on $\mathrm{ZnO}$ films. ${ }^{48,49}$ The $E_{\mathrm{a} 2}$ values of 24.4 and $44.8 \mathrm{meV}$ were obtained for $\mathrm{ZnO}: \mathrm{Ag}$ and $\mathrm{Ag} / \mathrm{ZnO}: \mathrm{Ag}$ thin films, respectively, which are widely assigned to the thermionic emission over grain boundaries. ${ }^{48,49}$ Figure $6 \mathrm{~b}$ also depicts the reduction in the conductance of $\mathrm{ZnO}: \mathrm{Ag}$ films after functionalization with $\mathrm{Ag}$ nanoparticles due to enhanced oxygen adsorption, which traps conduction electrons. ${ }^{48,49}$

3.6. Gas Sensing Properties of $\mathrm{Ag}(1) / \mathrm{ZnO}: \mathrm{Ag}$ and Ag(2)/ZnO:Ag Columnar Films. Figure $7 \mathrm{a}-\mathrm{c}$ shows the gas response of the $\mathrm{ZnO}: \mathrm{Ag}, \mathrm{Ag}(1) / \mathrm{ZnO}: \mathrm{Ag}$, and $\mathrm{Ag}(2) / \mathrm{ZnO}: \mathrm{Ag}$ columnar films to $1000 \mathrm{ppm}$ of $\mathrm{H}_{2}$ gas and $100 \mathrm{ppm}$ of VOC vapors (ethanol, acetone, $n$-butanol, 2-propanol, and methanol), respectively. As the carrier gas, the ambient air with $\sim 30 \%$ relative humidity $(\mathrm{RH})$ was used. Measurements in the temperature range between 200 and $350{ }^{\circ} \mathrm{C}$ were performed. For all samples, no considerable $\mathrm{H}_{2}$ response, even with using the highest concentration of $1000 \mathrm{ppm}$, was observed. The optimal operating temperature for the columnar $\mathrm{ZnO}: \mathrm{Ag}$ films is $250{ }^{\circ} \mathrm{C}$ (see Figure $7 \mathrm{a}$ ), where the gas responses to $100 \mathrm{ppm}$ of ethanol, acetone, $n$-butanol, 2-propanol, and methanol are $\sim 31, \sim 16.5, \sim 41, \sim 52.5$, and $\sim 31$, respectively. After functionalization with $\mathrm{Ag} \mathrm{NPs}$, the optimal operating temperature remained at $250{ }^{\circ} \mathrm{C}$ (see Figure $7 \mathrm{~b}, \mathrm{c}$ ), and the gas responses to $100 \mathrm{ppm}$ of ethanol, acetone, $n$-butanol, 2 propanol, and methanol are $\sim 74, \sim 48.5, \sim 67, \sim 82$, and $\sim 32$ for $\mathrm{Ag}(1) / \mathrm{ZnO}: \mathrm{Ag}$ and $~ 145, \sim 100, \sim 156, \sim 175$, and $\sim 54$ for $\mathrm{Ag}(2) / \mathrm{ZnO}: \mathrm{Ag}$, respectively. The gas response increased by adding Ag NPs, which are known to weaken the adsorption and desorption of adsorbates on metal oxides and accelerate their reaction with oxygen. ${ }^{50}$ Our results for the columnar $\mathrm{ZnO}: \mathrm{Ag}$ and Ag-functionalized $\mathrm{ZnO}: \mathrm{Ag}$ films are highly improved compared to reports for the undoped and Agmodified $\mathrm{ZnO}$ micro and columnar films ${ }^{18}$ (see Table 1). The possible mechanism for such improved performances is discussed in Section 3.7.

Figure $7 \mathrm{~d}-\mathrm{f}$ and Figure $\mathrm{S} 7$ show the dynamic response of pristine and Ag-functionalized $\mathrm{ZnO}: \mathrm{Ag}$ columnar films, respectively, to $100 \mathrm{ppm}$ of VOC vapors at different operating temperatures. We observed that all samples show fast response recoveries after evacuation of the VOC vapor from the test chamber. The calculated response and recovery times decrease with the operating temperatures are presented in Figure S8a for $\mathrm{ZnO}: \mathrm{Ag}$, Figure S8b for $\mathrm{Ag}(1) / \mathrm{ZnO}: \mathrm{Ag}$, and Figure S8c for $\mathrm{Ag}(2) / \mathrm{ZnO}: \mathrm{A}$. The calculated gas sensing parameters including the response value as well as the response and recovery times are summarized in Table $\mathrm{S} 1$ for $\mathrm{ZnO}: \mathrm{Ag}$, $\mathrm{Ag}(1) / \mathrm{ZnO}: \mathrm{Ag}$, and $\mathrm{Ag}(2) / \mathrm{ZnO}: \mathrm{Ag}$ columnar films.

The dependence of gas response $(S)$ versus concentration of VOC vapors $\left(p_{\mathrm{VOC}}\right)$ for $\mathrm{ZnO}: \mathrm{Ag}, \mathrm{Ag}(1) / \mathrm{ZnO}: \mathrm{Ag}$, and $\mathrm{Ag}(2) /$ $\mathrm{ZnO}: \mathrm{Ag}$ columnar films is presented in Figure $7 \mathrm{~g}-\mathrm{i}$, respectively. All samples showed a power law relationship to the varied VOC concentrations (from 10 to $500 \mathrm{ppm}$ ), $S \propto$ $p_{\text {VOC }}^{\beta}$, where $\beta$ is the slope of $\log S$ versus $\log p_{\text {VOC. }}{ }^{27}$ For all samples, $\beta$ varies from 0.5 to 0.67 . The theoretical detection limits (DL) were estimated from Figure $7 \mathrm{~g}-\mathrm{i}$, as was reported by Dua et al. ${ }^{51}$ The estimated values of $\mathrm{DL}$ for ethanol, acetone, $n$-butanol, 2-propanol, and methanol are 0.48, 0.66, 

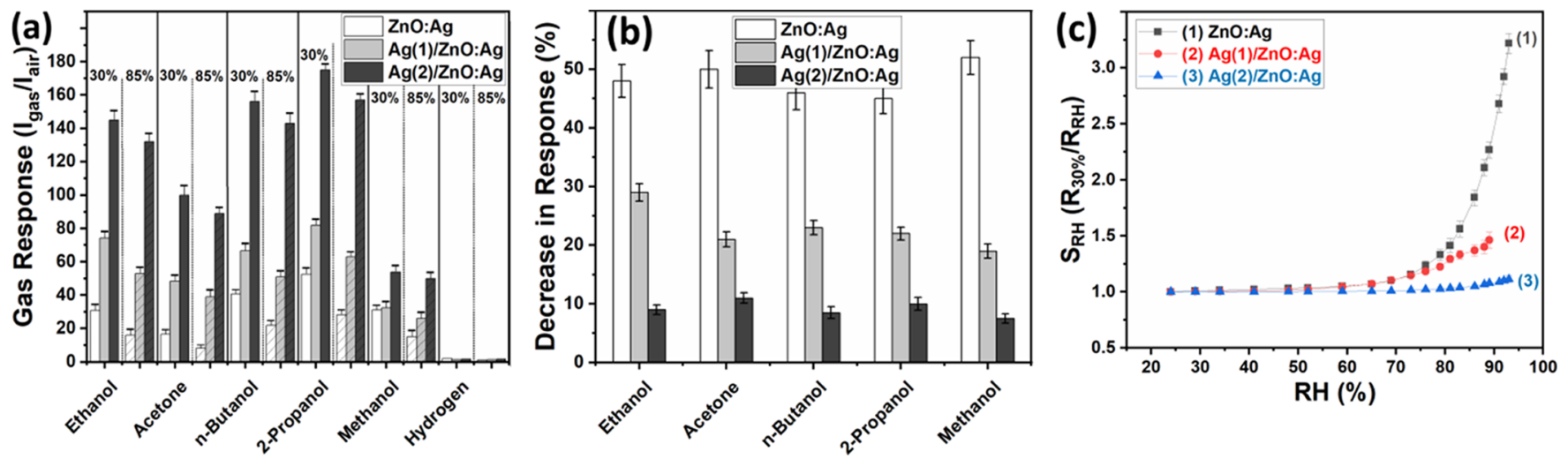

Figure 8. (a) Calculated gas response at $250{ }^{\circ} \mathrm{C}$ operating temperature for $\mathrm{ZnO}: \mathrm{Ag}, \mathrm{Ag}(1) / \mathrm{ZnO}: \mathrm{Ag}$, and $\mathrm{Ag}(2) / \mathrm{ZnO}: \mathrm{Ag}$ columnar films to 100 ppm of VOC vapors and $1000 \mathrm{ppm}$ of $\mathrm{H}_{2}$ gas under different relative humidity conditions (30 and 85\%). (b) Calculated decrease in response at $250{ }^{\circ} \mathrm{C}$ operating temperature to $100 \mathrm{ppm}$ of VOC vapors by increasing the $\mathrm{RH}$ from 30 to $85 \%$. (c) Room temperature response of $\mathrm{ZnO}: \mathrm{Ag}$, $\mathrm{Ag}(1) / \mathrm{ZnO}: \mathrm{Ag}$, and $\mathrm{Ag}(2) / \mathrm{ZnO}: \mathrm{Ag}$ versus relative humidity.

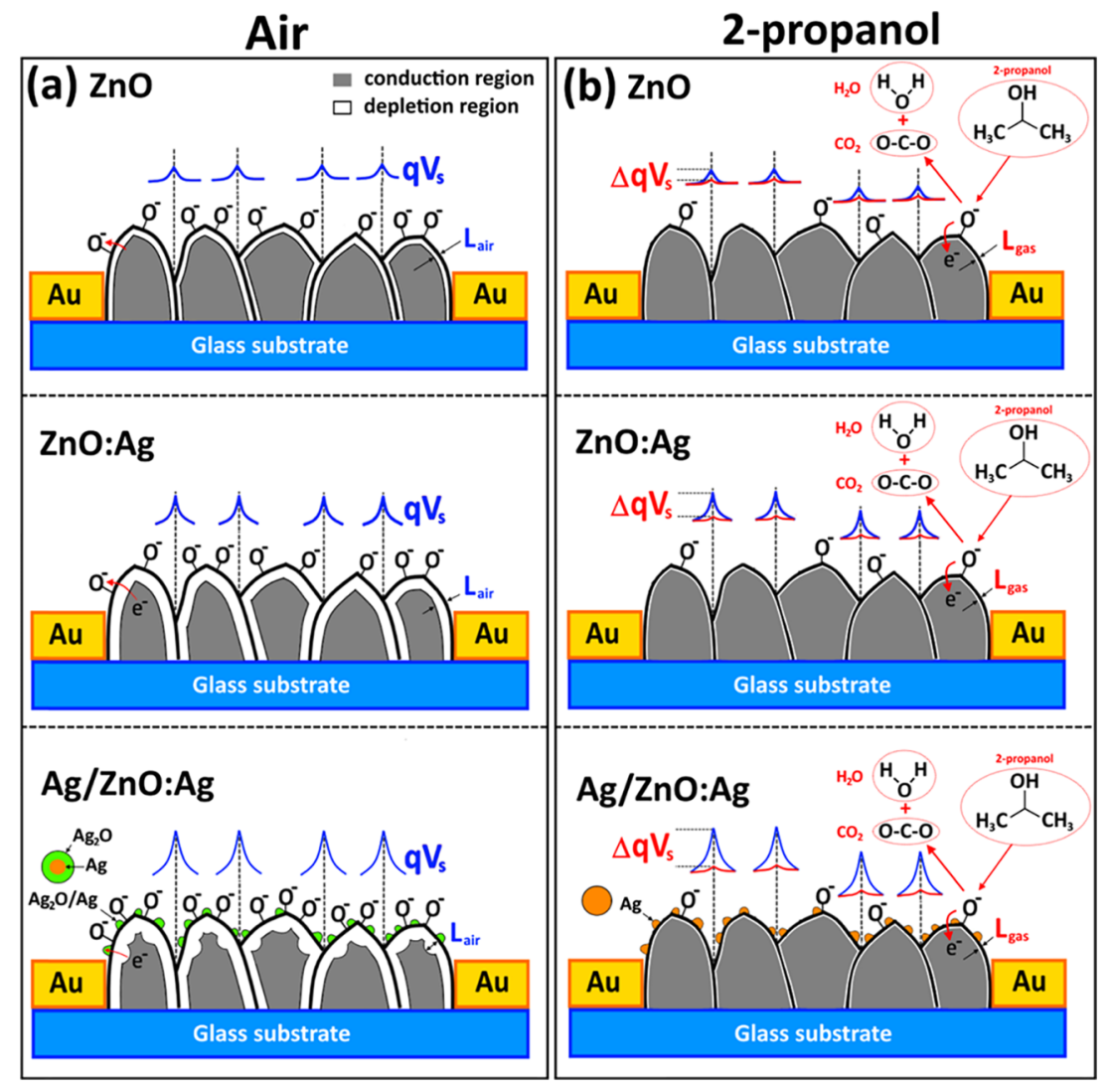

Figure 9. Proposed gas sensing mechanism for $\mathrm{ZnO}, \mathrm{ZnO}: \mathrm{Ag}$, and $\mathrm{Ag} / \mathrm{ZnO}: \mathrm{Ag}$ columnar films integrated in sensor structures during exposure to: (a) ambient air and (b) 2-propanol vapors.

$0.22,0.13$, and $0.06 \mathrm{ppm}$ for $\mathrm{ZnO}: \mathrm{Ag}, 0.1,0.17,0.21,0.05$, and $0.37 \mathrm{ppm}$ for $\mathrm{Ag}(1) / \mathrm{ZnO}: \mathrm{Ag}$, and $0.02,0.07,0.04,0.01$, and $0.24 \mathrm{ppm}$ for $\mathrm{Ag}(2) / \mathrm{ZnO}: \mathrm{Ag}$ columnar films, respectively. Therefore, by functionalization with higher density of Ag NPs, we can effectively decrease the detection limit of our columnar films, which for ethanol is in excellent agreement with the value of $10 \mathrm{ppb}$ found for $\mathrm{NiO}-\mathrm{ZnO} \mathrm{p}-\mathrm{n}$ nanoheterojunction networks. $^{52}$ The gas response and DL of samples are summarized in Table S2.

Variation in the atmospheric humidity levels is an important factor that determines the sensing properties of gas sensors based on the metal oxide micro and nanostructures due to the hydroxyl poisoning. ${ }^{6,7}$ Therefore, we performed the gas sensing measurements at a low RH value of $\sim 30 \%$ and high $\mathrm{RH}$ value of $\sim 85 \%$, respectively. The higher value of $\mathrm{RH}$ was generated using a bubbling system. ${ }^{27}$

Figure 8a shows the gas response to $100 \mathrm{ppm}$ of VOC vapors and 1000 ppm of $\mathrm{H}_{2}$ gas for $\mathrm{ZnO}: \mathrm{Ag}, \mathrm{Ag}(1) / \mathrm{ZnO}: \mathrm{Ag}$, and $\mathrm{Ag}(2) / \mathrm{ZnO}: \mathrm{Ag}$ samples at an optimal operating temperature of $250{ }^{\circ} \mathrm{C}$ under different conditions of relative humidity $(\mathrm{RH})$, that is, at a lower value of $30 \%$ and a higher value of $85 \%$. The decrease in response for all samples by the increase in $\mathrm{RH}$ was observed (see Table S3). In the case of the $\mathrm{ZnO}: \mathrm{Ag}$ columnar film, by increasing RH from 30 to $85 \%$, the decreases 

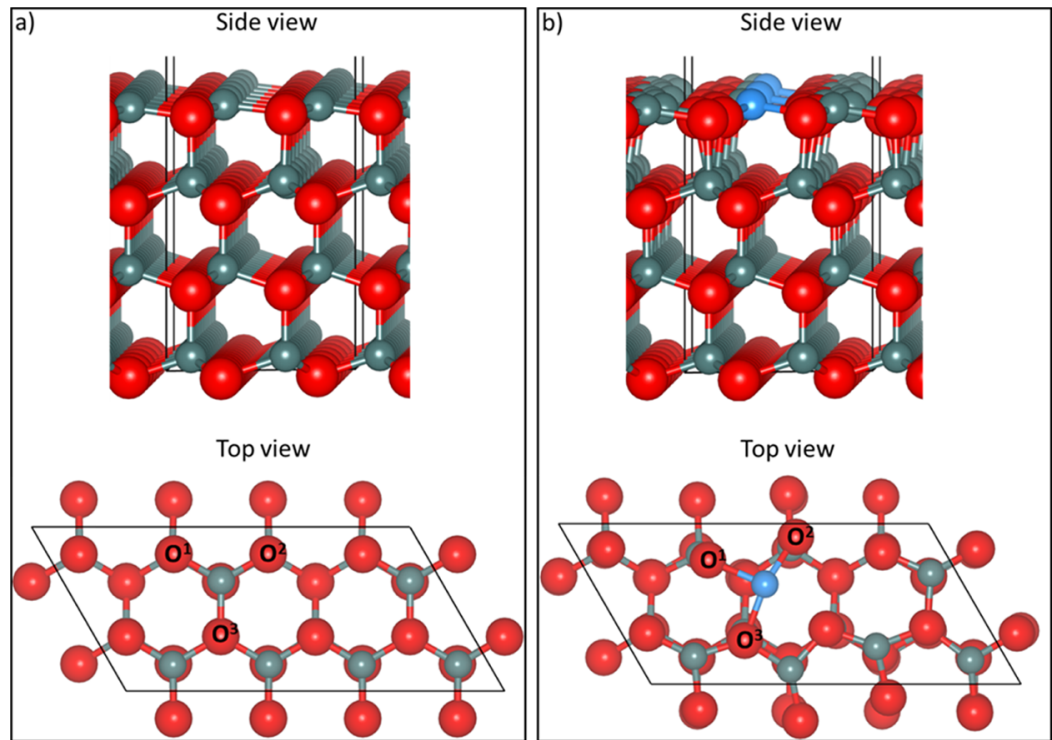

Figure 10. (Top panel) side and (bottom panel) top views of the (a) relaxed $\mathrm{ZnO}(0001)$ pristine surface and (b) Ag-doped $\mathrm{ZnO}$ (0001) surface. Color key: red, green, and blue represent $\mathrm{O}, \mathrm{Zn}$, and $\mathrm{Ag}$ atoms, respectively.

in response for $100 \mathrm{ppm}$ of ethanol, acetone, $n$-butanol, 2propanol, and methanol are $\sim 48, \sim 50, \sim 46, \sim 45$, and $\sim 52 \%$, respectively. After functionalization with Ag NPs, the lower decrease in response by increasing $\mathrm{RH}$ was observed. The decreases in response for $100 \mathrm{ppm}$ of ethanol, acetone, $n$ butanol, 2-propanol, and methanol is $\sim 29, \sim 21, \sim 23, \sim 22$, and $\sim 19 \%$, respectively, for $\mathrm{Ag}(1) / \mathrm{ZnO}: \mathrm{Ag}$ and $\sim 9, \sim 11, \sim 8.5$, $\sim 10$, and $\sim 7.5 \%$, respectively, for $\mathrm{Ag}(2) / \mathrm{ZnO}: \mathrm{Ag}$. Therefore, it is demonstrated that by surface functionalization of $\mathrm{ZnO}: \mathrm{Ag}$ columnar films with $\mathrm{Ag} \mathrm{NPs,} \mathrm{an} \mathrm{improvement} \mathrm{in} \mathrm{stability}$ under humidity changes can be achieved (see Figure $8 \mathrm{~b}$ ). These results may indicate that Ag NPs act as hydroxyl absorbers, which was also observed, for example, for $\mathrm{Sb}$ atoms ${ }^{6}$ and $\mathrm{CuO}^{53} \mathrm{Ag}$ NPs were found to be excellent humidity sensors with excellent stability. ${ }^{54,55}$ This can also explain the lower decrease in response by higher density of Ag NPs.

To experimentally demonstrate the lower dependence of resistance for $\mathrm{Ag} \mathrm{NP}$-functionalized $\mathrm{ZnO}$ :Ag columnar films on $\mathrm{RH}$, the room temperature measurements of resistance versus $\mathrm{RH}$ were performed, and the results are presented in Figure 8c. The $\mathrm{RH}$ response $\left(S_{\mathrm{RH}}\right)$ was defined as the ratio of the resistance under $30 \% \mathrm{RH}\left(R_{30 \%}\right)$ and under the measured $\mathrm{RH}$ value $\left(R_{\mathrm{RH}}\right)$. The larger change in resistance by increasing $\mathrm{RH}$ for samples without Ag NPs was observed, while by increasing the density of Ag NPs, the dependence of resistance on $\mathrm{RH}$ is lowered. These results reveal the excellent potential of Ag NPfunctionalized $\mathrm{ZnO}: \mathrm{Ag}$ columnar films for real-time environmental monitoring.

3.7. Proposed Gas Sensing Mechanism for Columnar Films. The gas sensing mechanism of the undoped $\mathrm{ZnO}$ columnar films was already discussed in our previous work. ${ }^{18}$ We explained the gas sensing mechanism based on the modulation of potential barriers $\left(q \Delta V_{\mathrm{S}}\right)$ between the $\mathrm{ZnO}$ grains due to adsorption/desorption of oxygen species, which modulates the surface electron depletion region. ${ }^{18} \mathrm{We}$ also discussed the role of the interconnection-interpenetration of the $\mathrm{ZnO}$ grains, enhancing the modulation of $q \Delta V_{S}$, which governs the gas response $(S)^{18}$

$$
S=\frac{R_{\mathrm{air}}}{R_{\mathrm{gas}}} \approx \exp \left(-\frac{q \Delta V_{S}}{2 k T}\right)
$$

where $R_{\text {air }}$ and $R_{\text {gas }}$ are the resistance in air and under gas exposure, respectively, and $q$ is the electrical charge of the carrier.

As we have already discussed in this work, doping with $\mathrm{Ag}$ generates more acceptors in $\mathrm{ZnO}$, which decrease the chargecarrier concentration $(n)$ and enlarge the electron depletion region $(L)^{12,18}$

$$
L=\left(2 \varepsilon_{\mathrm{ZnO}} \varepsilon_{0} V_{\mathrm{S}} / q n\right)^{1 / 2}
$$

where $\varepsilon_{\mathrm{ZnO}}$ is the dielectric constant of $\mathrm{ZnO}$ and $V_{\mathrm{S}}$ is the interfacial potential. ${ }^{12,18}$ Under air exposure, oxygen adsorb onto the surface of grains, which increases the length of $L_{\text {air }}$ for the Ag-doped samples, compared to the undoped $\mathrm{ZnO}$ (see Figure $9 a)^{12,18}$

$$
\begin{aligned}
& \mathrm{O}_{2}(g) \rightarrow \mathrm{O}_{2}(a d) \\
& \frac{1}{2} \mathrm{O}_{2}(a d)+\mathrm{e}^{-} \rightarrow \mathrm{O}^{-}(a d)
\end{aligned}
$$

For the Ag-functionalized samples, the $L_{\text {air }}$ value due to enhanced adsorption of oxygen species further increased. The excellent catalytic properties of $\mathrm{Ag}$ as dopant and NPs lead to increasing the length of the electron depletion region, $L_{\text {air }}$ $(\mathrm{ZnO})<L_{\text {air }}(\mathrm{ZnO}: \mathrm{Ag})<L_{\text {air }}(\mathrm{Ag} / \mathrm{ZnO}: \mathrm{Ag})$ (see Figure 9a). Our results clearly show that Ag NP functionalization of the $\mathrm{ZnO}: \mathrm{Ag}$ grains facilitates faster adsorption and desorption of the oxygen species as well as quicker capture of free electrons. ${ }^{56}$ We also found evidence that the surfaces of the $\mathrm{Ag}$ NPs are easily oxidized to $\mathrm{Ag}_{2} \mathrm{O}$ in air at the relatively low operating temperature of $250{ }^{\circ} \mathrm{C} .{ }^{14,56}$ We can justify the reactivity of the Ag NPs toward oxygen due to their large Helmholtz double layer, ${ }^{56}$ which allow them to act as efficient electron sinks. The oxygen adsorption on the surfaces of $\mathrm{Ag}_{2} \mathrm{O}$ leads to the electron extraction from $\mathrm{ZnO}: \mathrm{Ag}$ effectively extending the width of electron depletion region to the supporting grain (see Figure 9a). ${ }^{14,56}$ Given the direct relationship between $L$ and $V_{S}$, we found the same increasing 


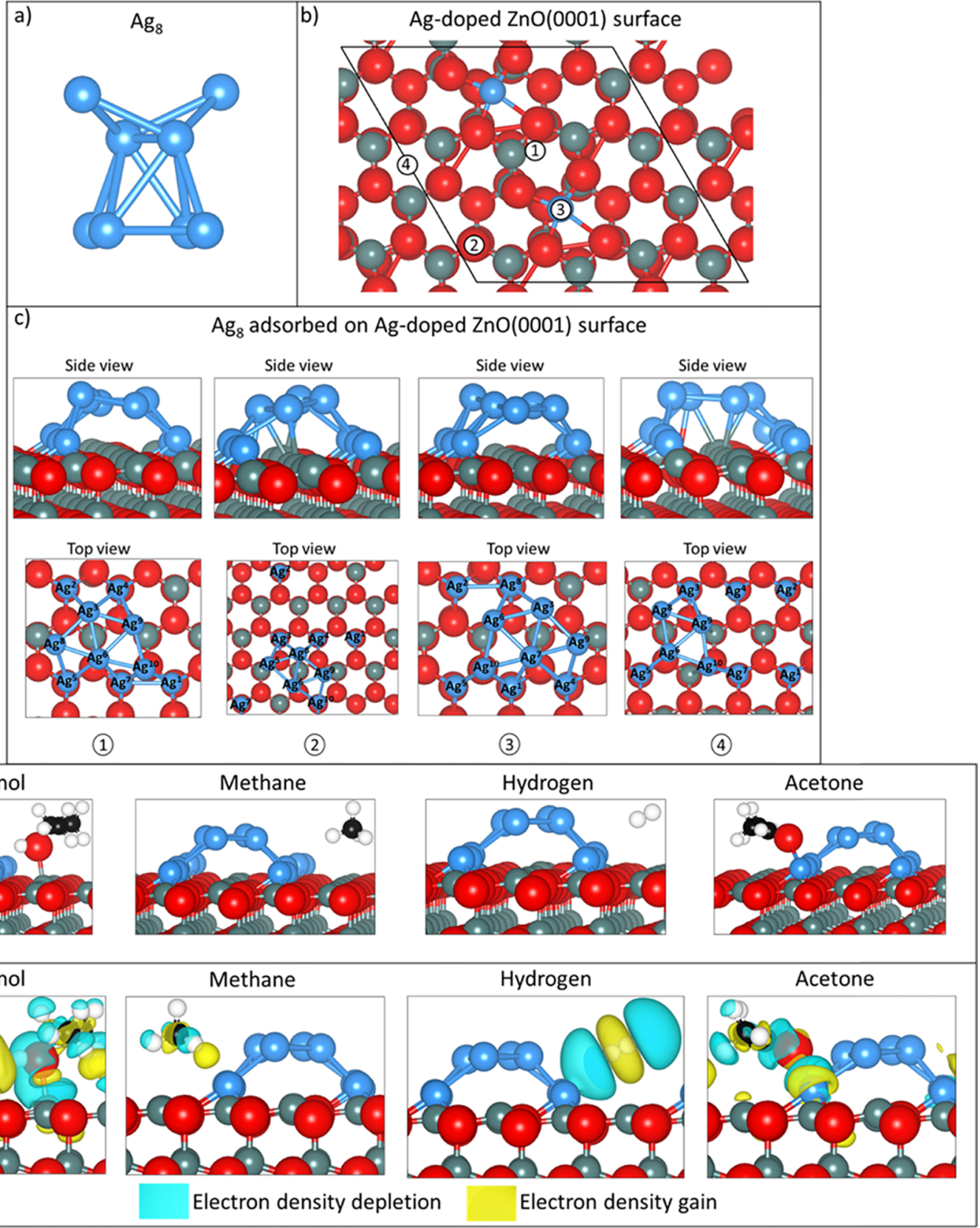

Figure 11. (a) Initial $\mathrm{Ag}_{8}$ cluster geometry. (b) Initial adsorption sites for the $\mathrm{Ag}_{8}$ center of mass: (1) between two dopant atoms, (2) near the dopant, (3) above the dopant, (4) and far away from the dopant. (c) Final adsorption geometries. (d) Most stable geometries and (e) electron density difference of propanol, methane, hydrogen, and acetone adsorbed on the $\mathrm{Ag}_{8} / \mathrm{ZnO}(0001)$ surface doped with $\mathrm{Ag}$. Color key: red, green, blue, black, and white represent $\mathrm{O}, \mathrm{Zn}, \mathrm{Ag}, \mathrm{C}$, and $\mathrm{H}$ atoms, respectively.

order for the potential barrier height $\left(q V_{S}\right)$, that is, $q V_{S}(\mathrm{ZnO})$ $<q V_{S}(\mathrm{ZnO}: \mathrm{Ag})<q V_{S}(\mathrm{Ag} / \mathrm{ZnO}: \mathrm{Ag})$ (see Figure $\left.9 \mathrm{a}\right)$.

We now focus on the detection of 2-propanol vapors $\left(\left(\mathrm{CH}_{3}\right)_{2} \mathrm{CHOH}\right)$ due to the slightly higher response compared to the other VOC gases. The gas sensing mechanism is similar for all VOC vapors, apart from the different reactions with oxygen species coadsorbed on the grain surfaces. ${ }^{57}$ The higher response to 2-propanol vapors compared to other VOC gases (see Figure 9b) can be explained based on the quantity of electrons released during the decomposition and oxidation, according to the reaction. ${ }^{57}$

$$
\left(\mathrm{CH}_{3}\right)_{2} \mathrm{CH}-\mathrm{OH}+9 \mathrm{O}^{-} \rightarrow 3 \mathrm{CO}_{2}+4 \mathrm{H}_{2} \mathrm{O}+9 \mathrm{e}^{-}
$$

Our results show that for the most effective $\mathrm{Ag} / \mathrm{ZnO}: \mathrm{Ag}$ sensor, the narrow electron depletion region $\left(L_{\text {gas }}\right)$ leads to the reduction of the potential barriers height $\left(q V_{S}\right)$ (see Figure $9 \mathrm{~b}$ ). According to eq 6, the highest modulation and gas response are reached using the $\mathrm{Ag} / \mathrm{ZnO}: \mathrm{Ag}$ samples, followed by $\mathrm{ZnO}: \mathrm{Ag}$ and then by $\mathrm{ZnO}$. For the $\mathrm{Ag} / \mathrm{ZnO}: \mathrm{Ag}$ samples, the $\mathrm{Ag}_{2} \mathrm{O}$ formed spontaneously on the surface of the NPs is reduced back to $\mathrm{Ag}$ under exposure to VOC vapors, providing electrons to $\mathrm{ZnO}^{14}$ and leading to an enhanced gas response. Thus, reported results support claims that hybrid $\mathrm{Me}_{x} \mathrm{O}_{y}$ and $\mathrm{Zn}_{x} \mathrm{Me}_{1-x} \mathrm{O}_{y}$ alloyed $\mathrm{ZnO}$ networks are very important for sensing applications. ${ }^{37,67,71}$

3.8. Density Functional Theory Simulations. 3.8.1. Pristine $\mathrm{ZnO}(0001)$ Surface. Computational details on DFT 
simulations are presented in the Supporting Information. Figure 10a shows the relaxed, clean $\mathrm{ZnO}(0001)$ surface where we observed an inward displacement of the $\mathrm{Zn}$ atoms belonging to the topmost layer during relaxation. The consequence of the displacements is the contraction of the $\mathrm{Zn}-\mathrm{O}$ bonds in the top two atomic layers. Before relaxation, the average $\mathrm{Zn}-\mathrm{O}$ distance is $1.947 \AA$, while after relaxation, this value drops to $1.860 \AA$. For the rest of the atoms in the surface slabs that were allowed to relax, we observed a negligible displacement.

3.8.2. Doped $\mathrm{ZnO}(0001)$ Surface. We next doped the $\mathrm{ZnO}(0001)$ surface with Ag. In the Experimental Section, the maximum $\mathrm{Ag}$ content considered is $1.3 \mathrm{wt} \%$. As our oxide surface cell contains 60 atoms, we replaced one $\mathrm{Zn}$ to obtain 1.7 wt \% of $\mathrm{Ag}$, which is close to the experimental doping concentration. Following our previous investigation ${ }^{20}$ where we showed that a metallic dopant prefers to occupy the most exposed surface site, we positioned the silver atom at the top layer (see Figure $10 \mathrm{~b}$ ). We found that the $\mathrm{Ag}$ atom moves away from its neighboring $\mathrm{O}$ atoms $\left(\mathrm{O}^{1}, \mathrm{O}^{2}\right.$, and $\mathrm{O}^{3}$ in Figure $10 \mathrm{~b}$ ) during optimization due to the larger ionic radii of $\mathrm{Ag}$ compared to $\mathrm{Zn}$ (see Experimental Section). This movement is observed mainly in the surface layer, as the average in-plane displacement of the silver atom is $0.220 \AA$ while the outward shift is $0.099 \AA$. Our simulations suggest that the $\mathrm{Zn}-\mathrm{O}$ bond distance around the Ag dopant undergoes an average decrease of $0.016 \AA$ following the creation of the defect. We note that similarly to $\mathrm{Ag}$, both $\mathrm{O}$ and $\mathrm{Zn}$ atoms move mainly in the direction of the surface plane.

The Bader charge analysis of $\mathrm{O}^{1}$ and $\mathrm{O}^{2}$ reveals that these atoms, which are equally charged, are oxidized by $0.1 \mathrm{e}^{-}$after doping. Thus, the charge transfer from Ag to the neighboring $\mathrm{O}$ is less important than the one from $\mathrm{Zn}$ to $\mathrm{O}$.

We next describe the $\mathrm{Zn}-\mathrm{O}$ and $\mathrm{Ag}-\mathrm{O}$ interaction by plotting the electronic density of states (DOS) of both the pristine and Ag-doped $\mathrm{Zn}(0001)$ surfaces (see Figure S9a,b). The calculated band gap of the pristine surface is $0.74 \mathrm{eV}$, which is in excellent agreement with the theoretical value of $0.75 \mathrm{eV}$ reported by Mohamad et al. ${ }^{58}$ We also note from Figure S9a,b that for both surfaces, the contribution to the valence band comes mainly from the $\mathrm{O} 2 \mathrm{p}$ orbitals. The $\mathrm{Zn} 3 \mathrm{~d}$ orbitals are dominant at lower energies, approximately between -8.00 and $-6.00 \mathrm{eV}$ and are thus expected to have less influence in the surface properties of the material than the $\mathrm{O}$ atoms.

We plotted the projected DOS of the $\mathrm{O}^{1}$ and $\mathrm{O}^{2} \mathrm{p}$ orbitals and the $d$ states of the metal atom bonded to them for both the pristine and Ag-doped $\mathrm{Zn}(0001)$ surfaces (see Figure S9c,d). In the pristine surface, as shown in Figure S9c, we note that just below the Fermi level, the $\mathrm{Zn} 3 \mathrm{~d}$ and $\mathrm{O}^{1}$ and $\mathrm{O}^{2} 2 \mathrm{p}$ orbitals are located at the same energy, at -0.19 and $-0.61 \mathrm{eV}$. The hybridization between those electronic states suggests a significant interaction between the atoms. From the DOS of the doped surface shown in Figure S9d, we note that just below the Fermi level, the intensities of the $\mathrm{Ag} 4 \mathrm{~d}$ orbitals and the neighboring oxygen $2 p$ orbitals are higher than the one found in the pristine surface. This suggests that in the doped surface, the $\mathrm{Ag}-\mathrm{O}$ interaction is stronger than $\mathrm{Zn}-\mathrm{O}$ in the clean surface. Thus, the $\mathrm{Ag}-\mathrm{O}$ interaction is less ionic, that is, more covalent, than the $\mathrm{Zn}-\mathrm{O}$ interaction, which is further supported by the smaller charge transfer from $\mathrm{Ag}$ to $\mathrm{O}$ than from $\mathrm{Zn}$ to $\mathrm{O}$.
3.8.3. Cluster Adsorption. We next evaluated the adsorption of the $\mathrm{Ag}_{8}$ cluster onto the Ag-doped $\mathrm{ZnO}(0001)$ surface (see Figure 11a). We tried four adsorption sites: between, close, on top, and away from the $\mathrm{Ag}$ dopant atoms (see Figure 11b). The initial $\mathrm{Ag}_{8}$ structure, prior to geometry optimization, was similar to the one employed by Idrobo et al. ${ }^{59}$ where they determined the ground state of [isolated] $\operatorname{Ag}_{n}(n=2-8)$ clusters. Thus, as shown in Figure 11a, we adopted a 3D shape where the average distance between the silver atoms is $2.72 \AA$. For all the configurations, we positioned the $\mathrm{Ag}_{8}$ cluster approximately $2 \AA$ above the oxide surface.

The optimized geometry of the initial adsorption site 1 shows that $\mathrm{Ag}_{8}$ tends to disaggregate as some of the $\mathrm{Ag}$ atoms leave the cluster to adsorb on the surface (see Figure 11c). Interestingly, we found that the cluster atoms filled the $\mathrm{Zn}$ vacancies that were created to quench the dipole moment (see the Computational Details Section). Figure 11c shows that $\mathrm{Ag}^{4}$, similarly to the Ag dopant, sits in the center of mass of the triangle formed by three oxygens. The adsorption site of $\mathrm{Ag}^{4}$ is similar to the highly symmetric site described by Lloyd et al. ${ }^{60}$ where they used lattice-based adaptive kinetic Monte Carlo (LatAKMC) to describe $\mathrm{Ag}$ adsorption on top of the polar $\mathrm{ZnO}(0001)$ surface. The average distance between $\mathrm{Ag}^{4}$ and its neighboring oxygens is $2.442 \AA$, which is close to the average dopant-surface oxygen distance of $2.208 \AA$. The same observation can be made for $\mathrm{Ag}^{5}$ and $\mathrm{Ag}^{7}$, which are located in the center of masses of the neighboring oxygen atoms at average distances of 2.303 and $2.263 \AA$, respectively.

Similarly, for the adsorption site number 3 , three $\mathrm{Ag}$ atoms leave the cluster to adsorb on the surface. The average distance between the detached $\mathrm{Ag}^{4}, \mathrm{Ag}^{5}$, and $\mathrm{Ag}^{8}$ and their neighboring oxygen atoms is $2.302,2.259$, and $2.279 \AA$, respectively.

In both adsorption sites 2 and 4, four $\mathrm{Ag}$ atoms leave the cluster to adsorb on the surface. Figure $11 \mathrm{c}$ shows that for both configurations, the leaving atoms $\left(\mathrm{Ag}^{3}, \mathrm{Ag}^{4}, \mathrm{Ag}^{7}\right.$, and $\mathrm{Ag}^{10}$ for configuration 2 and $\mathrm{Ag}^{3}, \mathrm{Ag}^{4}, \mathrm{Ag}^{5}$, and $\mathrm{Ag}^{7}$ for configuration 4) adsorb on the surface at average distances from their neighboring oxygen atoms between 2.244 and $2.304 \AA$, respectively. For the four adsorption configurations, the average distance between the remaining aggregated $\mathrm{Ag}$ atoms is $\sim 2.8 \AA$, with geometries similar to the clusters described by Idrobo et al. ${ }^{59}$ From the geometry analysis, we note that surrounding an adsorbed $\mathrm{Ag}_{8}$ cluster with $\mathrm{Ag}$ dopants would maintain the aggregated geometry of the cluster, favoring the Stranski-Krastanov growth that has been observed experimentally $^{61}$ and theoretically. ${ }^{60,62}$

We next calculated the clustering energy and found that the most stable structures are for configurations 2 and 4 (0.31 and $0.32 \mathrm{eV}$, respectively), while configurations 1 and 3 are slightly less stable ( 0.36 and $0.38 \mathrm{eV}$, respectively). These energy values suggest that the adsorption is stronger for the clusters placed away from the dopant. The positive clustering energies show that the clusters tend to aggregate rather than completely wet the surface, although their small values indicate a competition between these two processes.

We also calculated the average Bader charge of the cluster and found average charges of $+0.2,+0.3,+0.2$, and $+0.3 \mathrm{e}^{-}$for configurations $1,2,3$, and 4 , respectively. The charges are in line with the clustering energies as most positive clusters, that is, where we observe the strongest charge transfer to the surface, are found for the most stable configurations 2 and 4 . From the Bader analysis, we also observed a charge reorganization for all the configurations where some $\mathrm{Ag}$ 
atoms that are not directly bonded to the surface have a negative charge. This charge segregation within the Ag cluster has been observed previously by Hirunsit et al. ${ }^{63}$ in $\mathrm{Ag}_{13}$ clusters adsorbed on $\mathrm{Al}_{2} \mathrm{O}_{3}$.

3.8.4. Molecules Adsorption. We chose the most stable configuration, that is, configuration 2 (see Figure 11c), to study the interaction between $\mathrm{Ag}_{8} / \mathrm{ZnO}(0001)$ doped with $\mathrm{Ag}$ and propanol $\left(\mathrm{C}_{3} \mathrm{H}_{8} \mathrm{O}\right)$, methane $\left(\mathrm{CH}_{4}\right)$, hydrogen $\left(\mathrm{H}_{2}\right)$, and acetone $\left(\left(\mathrm{CH}_{3}\right)_{2} \mathrm{CO}\right)$. For each molecule, we considered several orientations and adsorption sites: at the interface between the $\mathrm{Ag}_{8}$ cluster and the $\mathrm{ZnO}$ surface, above the cluster, and far away from the cluster. However, we describe here only the most stable geometry.

Propanol adsorbs molecularly on the surface, and the most favorable adsorption site is far away from the cluster (see Figure 11d). The calculated binding energy is $-1.00 \mathrm{eV}$, and the molecule surface distance is $2.214 \AA$.

Propanol interacts with the surface through its hydroxyl termination, which becomes slightly weaker after adsorption as the $\mathrm{O}-\mathrm{H}$ distance increases by $0.020 \AA$. We also note a slight increase by $0.01 \AA$ of the $\mathrm{C}-\mathrm{H}$ bond distance for hydrogen facing the surface. The $\mathrm{OH}$-surface interaction is confirmed by the electron density difference plot where we observe a slight charge gain between the hydrogens facing the surface and the surface (see Figure 11e). However, the large charge accumulation (depletion) between the $\mathrm{OH}$ termination and the $\mathrm{Ag}_{8}$ cluster ( $\mathrm{Zn}$ surface atoms) further supports that the polar group is the main interaction center. We calculated the Bader charge of the $\mathrm{Zn}$ atom interacting with the propanol $\mathrm{OH}$ group and noted that the positive charge increases slightly from +1.1 to $+1.2 \mathrm{e}^{-}$after adsorption.

Acetone also adsorbs molecularly with a binding energy of $-0.88 \mathrm{eV}$ and prefers to interact with the doped $\mathrm{ZnO}(0001)$ surface through the carbonyl oxygen atom. Figure 11d shows the interaction between the acetone/oxygen and two Ag atoms adsorbed on the surface at $2.529 \AA$. Concerning the intramolecular bonds, the $\mathrm{C}=\mathrm{O}$ distance increases by 0.020 $\AA$, suggesting a weakening due to the interaction with the surface. The other internal distances are barely affected by the surface as we only observe a small contraction of $0.01 \AA$ of both $\mathrm{C}-\mathrm{C}$ bonds. The electron density difference shown in Figure 11e confirms the interaction between the acetone oxygen and the silver atoms as both depletion and gain occur between them. However, this is a charge rearrangement rather than a transfer as the Bader charge of the silver atoms involved in the interaction is unchanged after the molecule adsorption. Thus, the energetic, structural, and electronic analyses confirm that the acetone-surface interaction is weaker than the propanol-surface interaction.

Figure $11 \mathrm{~d}$ shows that both methane and hydrogen prefer to adsorb away from the cluster, interacting weakly with the surface as the calculated binding energies are -0.29 and -0.11 $\mathrm{eV}$, respectively. The distance analysis also confirms the weak adsorption: $\mathrm{CH}_{4}$ is positioned at $2.904 \AA$ from the surface while $\mathrm{H}_{2}$ is $3.123 \AA$ above the surface. Those distances are larger than the ones found for acetone and propanol. Additionally, the molecular internal distances are not affected by the adsorption, showing that the molecule-surface interaction is not strong enough. The electron density difference shows that only a polarization of the molecule orbitals takes place (see Figure 11e). The Bader charge analysis also proves that $\mathrm{CH}_{4}$ and $\mathrm{H}_{2}$ are physisorbed on the surface as all atomic charges remain unchanged after the adsorption. Our computational results suggest that the interaction is stronger for molecules containing oxygen atoms, which can coordinate the surface $\mathrm{Zn}$ or cluster $\mathrm{Ag}$ atoms.

\section{CONCLUSIONS}

In summary, we developed a novel strategy to modulate the density of Ag nanoparticles uniformly on nonplanar $\mathrm{ZnO}: \mathrm{Ag}$ columnar films by a one-step sputtering method followed by thermal annealing at $350{ }^{\circ} \mathrm{C}$. By elucidating the concerning mechanisms, we demonstrated the synergistic role of doping and surface functionalization using $\mathrm{Ag}$ nanoparticles in enhancing the gas sensing response and selectivity of semiconducting oxides, namely, $\mathrm{ZnO}$, toward specific volatile organic compounds. These results are important for the use of new hybrid sensing nanomaterials, which enable simpler differentiation between various VOCs. The latter can serve as biomarkers for diseases at early stages since VOCs detected in exhaled breath at the ppb level are related to several diseases.

The gas sensing properties of such hybrid materials showed that the Ag-functionalized $\mathrm{ZnO}: \mathrm{Ag}$ samples offer significantly improved VOC sensing properties in an operating temperature range of $150-200{ }^{\circ} \mathrm{C}$. The $\mathrm{Ag}$-doped and $\mathrm{Ag} \mathrm{NP}$-functionalized $\mathrm{ZnO}:$ Ag columnar films were successfully synthesized as a single crystalline columnar matrix via a cost-effective SCS method, which allows for deposition on almost any material. The computational simulations showed that a few $\mathrm{Ag}$ atoms disaggregate from the cluster, which prefers to sit far away from the dopant. The gas sensing properties toward ethanol, acetone, $n$-butanol, 2-propanol, and methanol vapors improved after doping the $\mathrm{ZnO}$ columnar films with Ag. Further enhancement of the sensing properties of the Ag-doped $\mathrm{ZnO}$ columnar films toward VOC vapors by surface functionalization with Ag NPs of diameters between 6 and $12 \mathrm{~nm}$ was obtained experimentally, which is in agreement with the computational simulations. The synergistic effect of the $\mathrm{Ag}$ dopant atoms and $\mathrm{Ag}$ clusters on the $\mathrm{ZnO}$ columnar films is found to be highly beneficial for the response toward the detection of VOC gases. Experimental and theoretical evidence confirmed the importance of both approaches, doping and surface functionalization at the same time, for advancing the nanotechnology and nanoscience of new functional materials. Our work shows that highly selective and sensitive sensors used to distinguish specific VOC molecules are essential not only for air quality monitoring and various industrial applications but also for a simple manner to detect biomarkers for early stage diseases.

\section{ASSOCIATED CONTENT}

\section{S Supporting Information}

The Supporting Information is available free of charge on the ACS Publications website at DOI: 10.1021/acsami.9b07275.

SEM image of $\mathrm{ZnO}: \mathrm{Ag}$ and $\mathrm{Ag} / \mathrm{ZnO}: \mathrm{Ag}$ columnar films at different magnifications; column size histogram of $\mathrm{ZnO}: \mathrm{Ag}$ columnar films with different contents of $\mathrm{Ag}$; Raman mapping for the $E_{2}$ (high) band (integrated between 420 and $450 \mathrm{~cm}^{-1}$ ) of the $\mathrm{ZnO}: \mathrm{Ag}$ columnar films and the deconvolution of the $300-460 \mathrm{~cm}^{-1}$ region using a Gaussian fit; XPS plot of the $\mathrm{Ag} 3 \mathrm{~d}$ lines of $\mathrm{ZnO}: \mathrm{Ag}$ with increased (10-fold) Ag doping concentration; dynamic response to $100 \mathrm{ppm}$ of VOC vapors for $\mathrm{ZnO}: \mathrm{Ag}$ and $\mathrm{Ag} / \mathrm{ZnO}: \mathrm{Ag}$ at different 
operating temperatures; response and recovery times as a function of temperature for $\mathrm{ZnO}: \mathrm{Ag}$ and $\mathrm{Ag} / \mathrm{ZnO}: \mathrm{Ag}$; electronic density of states (DOS) of the pristine and Ag-doped $\mathrm{ZnO}(0001)$ surfaces and atomic projected DOS of the pristine and Ag-doped $\mathrm{ZnO}(0001)$ surfaces (PDF)

\section{AUTHOR INFORMATION}

\section{Corresponding Authors}

*E-mail: SantosCarballalD@cardiff.ac.uk (D.S.-C.).

*E-mail: deLeeuwN@cardiff.ac.uk (N.H.d.L.).

*E-mail: ra@tf.uni-kiel.de (R.A.).

*E-mail: ff@tf.uni-kiel.de (F.F.).

*E-mail: ollu@tf.uni-kiel.de; oleg.lupan@mib.utm.md; lupan@ physics.ucf.edu (O.L.).

\section{ORCID $\odot$}

Franz Faupel: 0000-0003-3367-1655

\section{Author Contributions}

O.L., V.P., and A.V. synthesized the Ag-functionalized $\mathrm{ZnO}: \mathrm{Ag}$ material. O.L. developed synthesis from chemical solution procedure SCS for ZnO. O.L., V.P., A.V., M.-I.T., and M.H. adapted the technological approach for material synthesis and integration/fabrication of the sensors. A.V. and F.F. developed $\mathrm{Ag}$ functionalization procedure and setup and realized all experiments and XPS analysis. P.V. and O.L. carried out the measurement of sensing properties of sensors based on such structures and analyzed data. T.D. and L.K. studied TEM. V.P., O.L., M.H., R.A., and M.-I.T. analyzed the results, including Raman data and revised draft. N.H.d.L., D.S.-C., and A.C.-E. realized the computational part. A.V., P.V., A.C.-E., D.S.-C., R.A, and O.L. drafted the article. O.L., F.F., N.H.d.L., L.K., and R.A. conceived and designed the study and approved the final version of the manuscript to be published. All authors reviewed the manuscript.

\section{Notes}

The authors declare no competing financial interest.

\section{ACKNOWLEDGMENTS}

Dr. Lupan acknowledges the Alexander von Humboldt Foundation for the research fellowship for experienced researchers 3-3MOL/1148833 STP at the Institute for Materials Science, Kiel University, Germany. The German Research Foundation (DFG) sponsored partially this research through the research unit FOR2093. This research was partly supported by the STCU and ASM within the Grant 6229A and by the Technical University of Moldova. We acknowledge the Engineering and Physical Sciences Research Council (EPSRC grant EP/K009567) for funding. Through our membership of the UK's HEC Materials Chemistry Consortium, which is funded by EPSRC (EP/L000202), this work used the ARCHER UK National Supercomputing Service (http:// www.archer.ac.uk). This work was performed using the computational facilities of the Advanced Research Computing at Cardiff (ARCCA) Division, Cardiff University. The authors also acknowledge the use of HPC Wales, Supercomputing Wales, and associated support services in the completion of this work. All data created during this research is openly available from the Cardiff University's Research Portal at http://doi.org/10.17035/d.2019.0081497456.

\section{REFERENCES}

(1) Righettoni, M.; Amann, A.; Pratsinis, S. E. Breath analysis by nanostructured metal oxides as chemo-resistive gas sensors. Mater. Today 2015, 18, 163-171.

(2) Wang, Z. L.; Song, J. Piezoelectric Nanogenerators Based on Zinc Oxide Nanowire Arrays. Science 2006, 312, 242.

(3) Hu, X.; Masuda, Y.; Ohji, T.; Kato, K. Micropatterning of $\mathrm{ZnO}$ Nanoarrays by Forced Hydrolysis of Anhydrous Zinc Acetate. Langmuir 2008, 24, 7614-7617.

(4) $\mathrm{Hu}, \mathrm{X}$.; Masuda, Y.; Ohji, T.; Kato, K. Fabrication of BlanketLike Assembled $\mathrm{ZnO}$ Nanowhiskers Using an Aqueous Solution. J. Am. Ceram. Soc. 2009, 92, 922-926.

(5) Hu, X.; Shen, X.; Huang, R.; Masuda, Y.; Ohji, T.; Kato, K. A facile template-free route to synthesize porous $\mathrm{ZnO}$ nanosheets with high surface area. J. Alloys Compd. 2013, 580, 373-376.

(6) Suematsu, K.; Sasaki, M.; Ma, N.; Yuasa, M.; Shimanoe, K. Antimony-Doped Tin Dioxide Gas Sensors Exhibiting High Stability in the Sensitivity to Humidity Changes. ACS Sens. 2016, 1, 913-920.

(7) Bai, Z.; Xie, C.; Hu, M.; Zhang, S.; Zeng, D. Effect of Humidity on the Gas Sensing Property of the Tetrapod-Shaped $\mathrm{ZnO}$ Nanopowder Sensor. Mater. Sci. Eng. B 2008, 149, 12-17.

(8) Lupan, O.; Postica, V.; Labat, F.; Ciofini, I.; Pauporté, T.; Adelung, R. Ultra-Sensitive and Selective Hydrogen Nanosensor With Fast Response at Room Temperature Based on a Single Pd/ZnO Nanowire. Sens. Actuators, B 2018, 254, 1259-1270.

(9) Gröttrup, J.; Postica, V.; Ababii, N.; Lupan, O.; Zamponi, C.; Meyners, D.; Mishra, Y. K.; Sontea, V.; Tiginyanu, I.; Adelung, R. Size-Dependent UV and Gas Sensing Response of Individual $\mathrm{Fe}_{2} \mathrm{O}_{3}$ ZnO:Fe Micro- and Nanowire Based Devices. J. Alloys Compd. 2017, 701, 920-925.

(10) Lupan, O.; Postica, V.; Gröttrup, J.; Mishra, A. K.; de Leeuw, N. H.; Adelung, R. Enhanced UV and ethanol vapour sensing of a single 3-D $\mathrm{ZnO}$ tetrapod alloyed with $\mathrm{Fe}_{2} \mathrm{O}_{3}$ nanoparticles. Sens. Actuators, B 2017, 245, 448-461.

(11) Yamazoe, N. New approaches for improving semiconductor gas sensors. Sens. Actuators, B 1991, 5, 7-19.

(12) Lupan, O.; Cretu, V.; Postica, V.; Ahmadi, M.; Cuenya, B. R.; Chow, L.; Tiginyanu, I.; Viana, B.; Pauporté, T.; Adelung, R. Silverdoped zinc oxide single nanowire multifunctional nanosensor with a significant enhancement in response. Sens. Actuators, B 2016, 223, 893-903.

(13) Lupan, O.; Postica, V.; Marx, J.; Mecklenburg, M.; Mishra, Y. K.; Schulte, K.; Fiedler, B.; Adelung, R. Individual hollow and mesoporous aero-graphitic microtube based devices for gas sensing applications. Appl. Phys. Lett. 2017, 110, 263109.

(14) Hwang, I.-S.; Choi, J.-K.; Woo, H.-S.; Kim, S.-J.; Jung, S.-Y.; Seong, T.-Y.; Kim, I.-D.; Lee, J.-H. Facile control of $\mathrm{C}_{2} \mathrm{H}_{5} \mathrm{OH}$ sensing characteristics by decorating discrete $\mathrm{Ag}$ nanoclusters on $\mathrm{SnO}_{2}$ nanowire networks. ACS Appl. Mater. Interfaces 2011, 3, 3140-3145.

(15) Joshi, R. K.; Kruis, F. E.; Dmitrieva, O. Gas Sensing Behavior of $\mathrm{SnO}_{1.8}: \mathrm{Ag}$ Films Composed of Size-Selected Nanoparticles. J. Nanopart. Res. 2006, 8, 797-808.

(16) Shishiyanu, S. T.; Shishiyanu, T. S.; Lupan, O. I. Sensing characteristics of tin-doped $\mathrm{ZnO}$ thin films as $\mathrm{NO}_{2}$ gas sensor. Sens. Actuators, B 2005, 107, 379-386.

(17) Lupan, O.; Chow, L.; Shishiyanu, S.; Monaico, E.; Shishiyanu, T.; Şontea, V.; Cuenya, B. R.; Naitabdi, A.; Park, S.; Schulte, A. Nanostructured zinc oxide films synthesized by successive chemical solution deposition for gas sensor applications. Mater. Res. Bull. 2009, 44, 63-69.

(18) Postica, V.; Hölken, I.; Schneider, V.; Kaidas, V.; Polonskyi, O.; Cretu, V.; Tiginyanu, I.; Faupel, F.; Adelung, R.; Lupan, O. Multifunctional device based on $\mathrm{ZnO}: \mathrm{Fe}$ nanostructured films with enhanced UV and ultra-fast ethanol vapour sensing. Mater. Sci. Semicond. Process. 2016, 49, 20-33.

(19) Postica, V.; Hoppe, M.; Gröttrup, J.; Hayes, P.; Röbisch, V.; Smazna, D.; Adelung, R.; Viana, B.; Aschehoug, P.; Pauporté, T.; Lupan, O. Morphology dependent UV photoresponse of Sn-doped $\mathrm{ZnO}$ microstructures. Solid State Sci. 2017, 71, 75-86. 
(20) Postica, V.; Vahl, A.; Strobel, J.; Santos-Carballal, D.; Lupan, O.; Cadi-Essadek, A.; de Leeuw, N. H.; Schütt, F.; Polonskyi, O.; Strunskus, T.; Baum, M.; Kienle, L.; Adelung, R.; Faupel, F. Tuning doping and surface functionalization of columnar oxide films for volatile organic compound sensing: experiments and theory. J. Mater. Chem. A 2018, 6, 23669-23682.

(21) Lupan, O.; Shishiyanu, S.; Ursaki, V.; Khallaf, H.; Chow, L.; Shishiyanu, T.; Sontea, V.; Monaico, E.; Railean, S. Synthesis of nanostructured Al-doped zinc oxide films on $\mathrm{Si}$ for solar cells applications. Sol. Energy Mater. Sol. Cells 2009, 93, 1417-1422.

(22) Vahl, A.; Strobel, J.; Reichstein, W.; Polonskyi, O.; Strunskus, T.; Kienle, L.; Faupel, F. Single target sputter deposition of alloy nanoparticles with adjustable composition via a gas aggregation cluster source. Nanotechnology 2017, 28, 175703.

(23) Polonskyi, O.; Peter, T.; Mohammad Ahadi, A.; Hinz, A.; Strunskus, T.; Zaporojtchenko, V.; Biederman, H.; Faupel, F. Huge increase in gas phase nanoparticle generation by pulsed direct current sputtering in a reactive gas admixture. Appl. Phys. Lett. 2013, 103, No. 033118.

(24) Haberland, H.; Karrais, M.; Mall, M.; Thurner, Y. Thin films from energetic cluster impact: A feasibility study. J. Vac. Sci. Technol, A 1992, 10, 3266-3271.

(25) Lupan, O.; Cretu, V.; Postica, V.; Polonskyi, O.; Ababii, N.; Schütt, F.; Kaidas, V.; Faupel, F.; Adelung, R. Non-planar nanoscale $\mathrm{p}-\mathrm{p}$ heterojunctions formation in $\mathrm{Zn}_{\mathrm{x}} \mathrm{Cu}_{1-\mathrm{x}} \mathrm{O}_{\mathrm{y}}$ nanocrystals by mixed phases for enhanced sensors. Sens. Actuators, B 2016, 230, 832-843.

(26) Lupan, O.; Cretu, V.; Postica, V.; Ababii, N.; Polonskyi, O.; Kaidas, V.; Schütt, F.; Mishra, Y. K.; Monaico, E.; Tiginyanu, I.; Sontea, V.; Strunskus, T.; Faupel, F.; Adelung, R. Enhanced ethanol vapour sensing performances of copper oxide nanocrystals with mixed phases. Sens. Actuators, B 2016, 224, 434-448.

(27) Cretu, V.; Postica, V.; Mishra, A. K.; Hoppe, M.; Tiginyanu, I.; Mishra, Y. K.; Chow, L.; de Leeuw, N. H.; Adelung, R.; Lupan, O. Synthesis, characterization and DFT studies of zinc-doped copper oxide nanocrystals for gas sensing applications. J. Mater. Chem. A 2016, 4, 6527-6539.

(28) Kresse, G.; Furthmüller, J. Efficient iterative schemes for $a b$ initio total-energy calculations using a plane-wave basis set. Phys. Rev. B 1996, 54, 11169-11186.

(29) Hohenberg, P.; Kohn, W. Inhomogeneous Electron Gas. Phys. Rev. 1964, 136, B864-B871.

(30) Perdew, J. P.; Burke, K.; Ernzerhof, M. Generalized Gradient Approximation Made Simple. Phys. Rev. Lett. 1996, 77, 3865-3868.

(31) Grimme, S.; Antony, J.; Ehrlich, S.; Krieg, H. A consistent and accurate $a b$ initio parametrization of density functional dispersion correction (DFT-D) for the 94 elements H-Pu. J. Chem. Phys. 2010, 132, 154104.

(32) Dudarev, S. L.; Botton, G. A.; Savrasov, S. Y.; Humphreys, C. J.; Sutton, A. P. Electron-energy-loss spectra and the structural stability of nickel oxide: An LSDA+U study. Phys. Rev. B 1998, 57, 15051509.

(33) Anisimov, V. I.; Korotin, M. A.; Zaanen, J.; Andersen, O. K. Spin bags, polarons, and impurity potentials in $\mathrm{La}_{2-\mathrm{x}} \mathrm{Sr}_{\mathrm{x}} \mathrm{CuO}_{4}$ from first principles. Phys. Rev. Lett. 1992, 68, 345-348.

(34) Allen, J. P.; Scanlon, D. O.; Watson, G. W. Electronic structures of silver oxides. Phys. Rev. B 2011, 84, 115141.

(35) Blöchl, P. E. Projector augmented-wave method. Phys. Rev. B 1994, 50, 17953-17979.

(36) Watson, G. W.; Kelsey, E. T.; de Leeuw, N. H.; Harris, D. J.; Parker, S. C. Atomistic simulation of dislocations, surfaces and interfaces in MgO. J. Chem. Soc., Faraday Trans. 1996, 92, 433-438.

(37) Lupan, O.; Postica, V.; Gröttrup, J.; Mishra, A. K.; de Leeuw, N. H.; Carreira, J. F. C.; Rodrigues, J.; Ben Sedrine, N.; Correia, M. R.; Monteiro, T.; Cretu, V.; Tiginyanu, I.; Smazna, D.; Mishra, Y. K.; Adelung, R. Hybridization of Zinc Oxide Tetrapods for Selective Gas Sensing Applications. ACS Appl. Mater. Interfaces 2017, 9, 40844099.

(38) Bader, R. F. W. A quantum theory of molecular structure and its applications. Chem. Rev. 1991, 91, 893-928.
(39) Chen, J.; Yan, X.; Liu, W.; Xue, Q. The ethanol sensing property of magnetron sputtered $\mathrm{ZnO}$ thin films modified by $\mathrm{Ag}$ ion implantation. Sens. Actuators, B 2011, 160, 1499-1503.

(40) Jeong, S. H.; Park, B. N.; Lee, S. B.; Boo, J.-H. Structural and optical properties of silver-doped zinc oxide sputtered films. Surf. Coat. Technol. 2005, 193, 340-344.

(41) Arguello, C. A.; Rousseau, D. L.; Porto, S. P. S. First-order raman effect in wurtzite-type crystals. Phys. Rev. 1969, 181, 13511363.

(42) Ye, J. D.; Gu, S. L.; Zhu, S. M.; Liu, S. M.; Zheng, Y. D.; Zhang, R.; Shi, Y.; Chen, Q.; Yu, H. Q.; Ye, Y. D. Raman study of lattice dynamic behaviors in phosphorus-doped $\mathrm{ZnO}$ films. Appl. Phys. Lett. 2006, 88, 101905.

(43) Tringe, J. W.; Levie, H. W.; McCall, S. K.; Teslich, N. E.; Wall, M. A.; Orme, C. A.; Matthews, M. J. Enhanced Raman scattering and nonlinear conductivity in Ag-doped hollow $\mathrm{ZnO}$ microspheres. Appl. Phys. A 2012, 109, 15-23.

(44) Shuang, D.; Wang, J. B.; Zhong, X. L.; Yan, H. L. Raman scattering and cathodoluminescence properties of flower-like manganese doped $\mathrm{ZnO}$ nanorods. Mater. Sci. Semicond. Process. 2007, 10, 97-102.

(45) Zeferino, R. S.; Flores, M. B.; Pal, U. Photoluminescence and Raman scattering in Ag-doped $\mathrm{ZnO}$ nanoparticles. J. Appl. Phys. 2011, 109, No. 014308.

(46) Moulder, J. Handbook of X-ray photoelectron spectroscopy: a reference book of standard spectra for identification and interpretation of XPS data; Chastain, J. Ed.; Physical Electronics Division, PerkinElmer Corporation: Eden Prairie, MN, 1992.

(47) Fan, J.; Freer, R. The roles played by $\mathrm{Ag}$ and $\mathrm{Al}$ dopants in controlling the electrical properties of $\mathrm{ZnO}$ varistors. J. Appl. Phys. 1995, 77, 4795-4800.

(48) Natsume, Y.; Sakata, H. Zinc oxide films prepared by sol-gel spin-coating. Thin Solid Films 2000, 372, 30-36.

(49) Natsume, Y.; Sakata, H.; Hirayama, T. Low-temperature electrical conductivity and optical absorption edge of $\mathrm{ZnO}$ films prepared by chemical vapour deposition. Phys. Status Solidi A 1995, 148, 485-495.

(50) Wu, R.-J.; Lin, D.-J.; Yu, M.-R.; Chen, M. H.; Lai, H.-F. Ag@ $\mathrm{SnO}_{2}$ core-shell material for use in fast-response ethanol sensor at room operating temperature. Sens. Actuators, B 2013, 178, 185-191.

(51) Dua, V.; Surwade, S. P.; Ammu, S.; Agnihotra, S. R.; Jain, S.; Roberts, K. E.; Park, S.; Ruoff, R. S.; Manohar, S. K. All-Organic Vapor Sensor Using Inkjet-Printed Reduced Graphene Oxide. Angew. Chem., Int. Ed. 2010, 122, 2200-2203.

(52) Chen, H.; Bo, R.; Shrestha, A.; Xin, B.; Nasiri, N.; Zhou, J.; Di Bernardo, I.; Dodd, A.; Saunders, M.; Lipton-Duffin, J.; White, T.; Tsuzuki, T.; Tricoli, A NiO-ZnO Nanoheterojunction Networks for Room-Temperature Volatile Organic Compounds Sensing. Adv. Opt. Mater. 2018, 6, 1800677.

(53) Choi, K.-I.; Kim, H.-J.; Kang, Y. C.; Lee, J.-H. Ultraselective and ultrasensitive detection of $\mathrm{H}_{2} \mathrm{~S}$ in highly humid atmosphere using $\mathrm{CuO}$-loaded $\mathrm{SnO}_{2}$ hollow spheres for real-time diagnosis of halitosis. Sens. Actuators, B 2014, 194, 371-376.

(54) Power, A. C.; Betts, A. J.; Cassidy, J. F. Silver nanoparticle polymer composite based humidity sensor. Analyst 2010, 135, 16451652.

(55) Thiwawong, T.; Onlaor, K.; Tunhoo, B. A humidity sensor based on silver nanoparticles thin film prepared by electrostatic spray deposition process. Adv. Mater. Sci. Eng. 2013, 2013, 640428.

(56) Tomer, V. K.; Duhan, S. Ordered mesoporous Ag-doped $\mathrm{TiO}_{2} /$ $\mathrm{SnO}_{2}$ nanocomposite based highly sensitive and selective VOC sensors. J. Mater. Chem. A 2016, 4, 1033-1043.

(57) Sysoev, V. V.; Schneider, T.; Goschnick, J.; Kiselev, I.; Habicht, W.; Hahn, H.; Strelcov, E.; Kolmakov, A. Percolating $\mathrm{SnO}_{2}$ nanowire network as a stable gas sensor: Direct comparison of long-term performance versus $\mathrm{SnO}_{2}$ nanoparticle films. Sens. Actuators, B 2009, 139, 699-703.

(58) Mohamad, A. A.; Hassan, M. S.; Yaakob, M. K.; Taib, M. F. M.; Badrudin, F. W.; Hassan, O. H.; Yahya, M. Z. A. First-principles 
calculation on electronic properties of zinc oxide by zinc-air system. J. King Saud Univ., Eng. Sci. 2017, 29, 278-283.

(59) Idrobo, J. C.; Ögüt, S.; Jellinek, J. Size dependence of the static polarizabilities and absorption spectra of $\mathrm{Ag}_{\mathrm{n}}(\mathrm{n}=2-8)$ clusters. Phys. Rev. B 2005, 72, No. 085445.

(60) Lloyd, A. L.; Smith, R.; Kenny, S. D. Critical island size for Ag thin film growth on $\mathrm{ZnO}\left(0001^{-}\right)$. Nucl. Instrum. Methods Phys. Res. Sect. B 2017, 393, 22-25.

(61) Duriau, E.; Agouram, S.; Morhain, C.; Seldrum, T.; Sporken, R.; Dumont, J. Growth of $\mathrm{Ag}$ thin films on $\mathrm{ZnO}(000-1)$ investigated by AES and STM. Appl. Surf. Sci. 2006, 253, 549-554.

(62) Lin, Z.; Bristowe, P. D. Microscopic characteristics of the $\mathrm{Ag}(111) / \mathrm{ZnO}(0001)$ interface present in optical coatings. Phys. Rev. B 2007, 75, 205423.

(63) Hirunsit, P.; Shimizu, K.-i.; Fukuda, R.; Namuangruk, S.; Morikawa, Y.; Ehara, M. Cooperative $\mathrm{H}_{2}$ Activation at Ag Cluster/ $\theta$ $\mathrm{Al}_{2} \mathrm{O}_{3}(110)$ Dual Perimeter Sites: A Density Functional Theory Study. J. Phys. Chem. C 2014, 118, 7996-8006.

(64) Tarwal, N. L.; Rajgure, A. V.; Patil, J. Y.; Khandekar, M. S.; Suryavanshi, S. S.; Patil, P. S.; Gang, M. G.; Kim, J. H.; Jang, J. H. A selective ethanol gas sensor based on spray-derived $\mathrm{Ag}-\mathrm{ZnO}$ thin films. J. Mater. Sci. 2013, 48, 7274-7282.

(65) Sun, Z.-P.; Liu, L.; Zhang, L.; Jia, D.-Z. Rapid synthesis of ZnO nano-rods by one-step, room-temperature, solid-state reaction and their gas-sensing properties. Nanotechnology 2006, 17, 2266.

(66) Wei, Y.; Wang, X.; Yi, G.; Zhou, L.; Cao, J.; Sun, G.; Chen, Z.; Bala, H.; Zhang, Z. Hydrothermal synthesis of $\mathrm{Ag}$ modified $\mathrm{ZnO}$ nanorods and their enhanced ethanol-sensing properties. Mater. Sci. Semicond. Process. 2018, 75, 327-333.

(67) Ding, J.; Zhu, J.; Yao, P.; Li, J.; Bi, H.; Wang, X. Synthesis of $\mathrm{ZnO}-\mathrm{Ag}$ hybrids and their gas-sensing performance toward ethanol. Ind. Eng. Chem. Res. 2015, 54, 8947-8953.

(68) Xiang, Q.; Meng, G.; Zhang, Y.; Xu, J.; Xu, P.; Pan, Q.; Yu, W. $\mathrm{Ag}$ nanoparticle embedded- $\mathrm{ZnO}$ nanorods synthesized via a photochemical method and its gas-sensing properties. Sens. Actuators, B 2010, 143, 635-640.

(69) Xing, X.; Xiao, X.; Wang, L.; Wang, Y. Highly sensitive formaldehyde gas sensor based on hierarchically porous Ag-loaded $\mathrm{ZnO}$ heterojunction nanocomposites. Sens. Actuators, B 2017, 247, 797-806.

(70) Ma, L.; Ma, S. Y.; Kang, H.; Shen, X. F.; Wang, T. T.; Jiang, X. H. K.; Chen, Q. Preparation of Ag-doped $\mathrm{ZnO}-\mathrm{SnO} 2$ hollow nanofibers with an enhanced ethanol sensing performance by electrospinning. Mater. Lett. 2017, 209, 188-192.

(71) Gröttrup, J.; Postica, V.; Smazna, D.; Hoppe, M.; Kaidas, V.; Mishra, Y. K.; Lupan, O.; Adelung, R. UV detection properties of hybrid ZnO tetrapod 3-D networks. Vacuum 2017, 146, 492-500. 